\title{
ARTE RUPESTRE ENTRE LAS SIERRAS Y LOS LLANOS RIOJANOS: LOCALIDAD ARQUEOLÓGICA PALANCHO
}

\section{María Pía Falchi ${ }^{1}$, M. Mercedes Podestá ${ }^{1}$, Diana S. Rolandi ${ }^{1}$, Anahí $\mathbf{R e}^{2}$ y Marcelo A. Torres ${ }^{1}$}

\author{
${ }^{1}$ Instituto Nacional de Antropología y Pensamiento Latinoamericano (INAPL). mpiafalchi@gmail.com, \\ mercedespodesta@yahoo.com, rolandidiana@gmail.com, marcel art@yahoo.com.ar \\ ${ }^{2}$ INAPL-CONICET anahire@inapl.gov.ar
}

Presentado el: 07/07/2011 - Aceptado 23/08/2011

\section{Resumen}

Este artículo presenta la localidad arqueológica con arte rupestre Palancho (Depto. Chilecito, La Rioja). Dadas las dimensiones de la localidad investigada y la abundancia de representaciones rupestres, este trabajo tiene como objetivo realizar una primera caracterización general de la localidad y proponer una secuencia cronológica preliminar para el arte rupestre. Para ello se toman en cuenta cuatro variables (técnica, tipos de motivos, superposiciones y grados de pátina) para agrupar las representaciones rupestres y proponer cinco momentos de ejecución. Por otra parte, ante la ausencia de otra evidencia arqueológica para el análisis se recurrió a indicadores estilísticos regionales.

Palabras claves: Arte rupestre, grabados, La Aguada, Sanagasta, La Rioja.

\begin{abstract}
This paper presents the archaeological site with rock art Palancho (Depto. Chilecito, La Rioja). Given the extension of the site and the number of representations, the main purpose of this presentation is to do a first preliminary description of the site and to propose a chronological sequence for rock art representations. To accomplish this goal four variables were analyzed (techniques, types of motifs, superimpositions and different desert varnish shades) in order to make five groups of representations from different chronological periods.

Also, because of the absence of other archeological remains, stylistic regional indicators were used.
\end{abstract}

Keywords: Rock art, engravings, La Aguada, Sanagasta, La Rioja.

\section{Introducción y antecedentes}

El objetivo de este artículo es presentar la localidad arqueológica con arte rupestre Palancho (Depto. Chilecito, La Rioja) (Fig. 1). Las amplias dimensiones de esta localidad y la gran cantidad de representaciones circunscriben el objetivo de este trabajo a llevar a cabo una primera caracterización general de la localidad y proponer una secuencia cronológica preliminar para el arte rupestre. 
Hasta el momento las investigaciones arqueológicas en la provincia de La Rioja se concentraron en regiones alejadas a la localidad de Palancho (Sur del departamento de Chilecito). En Raviña y Callegari (1988) puede consultarse la bibliografía editada hasta la década de 1980 y en Renard (1988) la relacionada al arte rupestre en particular. Con respecto a los trabajos desarrollados en regiones más próximas a la localidad de Palancho, pueden mencionarse la de Los Llanos riojanos (Sitio Guasamayo)(de Aparicio 1939; Cáceres Freyre 1956-57), Parque Nacional Talampaya (Schobinger 1966; Giordano y Gonaldi 1991; Ferraro 2005), entre otros. Actualmente el INAPL continua con los trabajos en Los Colorados (Falchi y Torres 2010), y recientemente inició investigaciones arqueológicas en las proximidades de la localidad de El Chiflón, La Rioja (Guráieb et al. 2010-11). En la provincia vecina de San Juan, el INAPL continua con las investigaciones en el Parque Provincial Ischigualasto y Sierra de Valle Fértil (Re et al. 2009 y en este volumen). Por su parte, Cahiza investiga el poblamiento tardío en el sector sur de la misma Sierra y en la Sierra de la Huerta (Cahiza 2007).

Palancho carecía de investigaciones sistemáticas antes de 2002, pero contaba con menciones en notas periodísticas en diarios y publicaciones locales dadas a conocer entre 1973 y 1992. Asimismo se tiene conocimiento de la visita de Cáceres Freyre, si bien no se cuenta con documentación de su autoría. Más tarde Schobinger realizó una documentación de la localidad (com. pers.) pero ésta nunca se divulgó. Sólo hizo una breve mención en una obra de carácter general con respecto a la gran profusión de motivos abstracto-geométricos observados (Schobinger y Gradin 1985:70). En 2004 Ortiz Malmierca presentó una descripción de la localidad en una obra de carácter general sobre arqueología riojana (Ortiz Malmierca 2004).

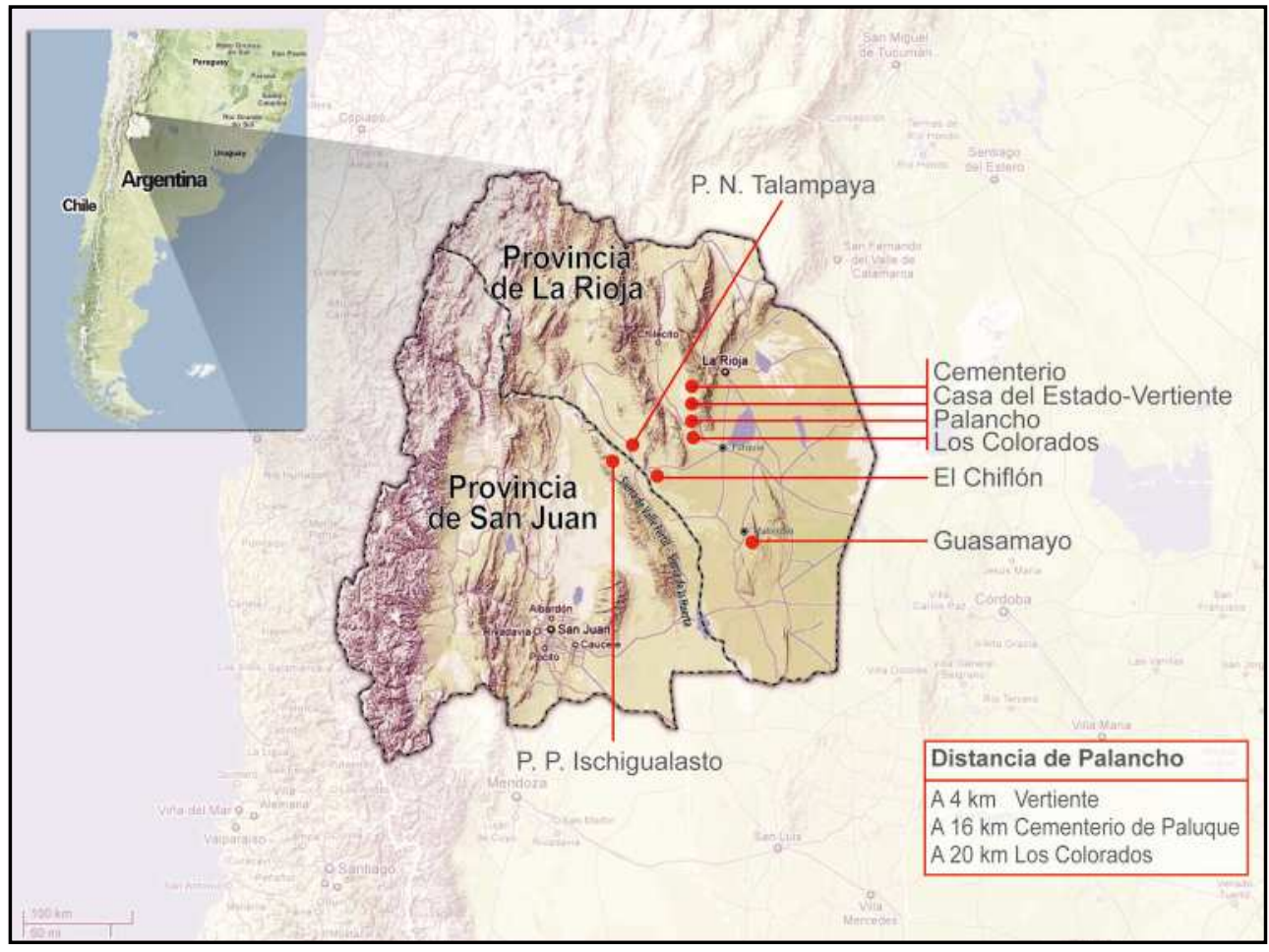

Figura 1. Ubicación de la localidad con arte rupestre Palancho y de otros sitios y localidades mencionados en las provincias de La Rioja y San Juan (Argentina). 
La localidad fue declarada de Interés Municipal en 1990 (ordenanza № 960). En 1991 se creó el Primer Reservorio Ecológico-Faunístico-Arqueológico (ordenanza 1173/91), y por último, en noviembre de 1992 el Destacamento "Perfil Incaico" en el paraje "el Palanche" (ordenanza $\mathrm{N}^{\circ} 1289$ ). Ambas tuvieron como principal foco de interés el mencionado sitio arqueológico, sin embargo estas nominaciones no se tradujeron en acciones concretas de protección.

En 2002, mediante la invitación de la Agencia de Cultura de la Provincia de La Rioja, arqueólogos del INAPL y miembros de la Agencia (Martha Ortiz Malmierca y Oscar Gutiérrez) iniciaron los primeros trabajos en el sitio Palancho, conocido también como Paluque, Paluqui, Perfil del Inca, SlarCH11 o, más recientemente, como Talampayita en alusión al Parque Nacional Talampaya, uno de los polos del turismo riojano. Estas primeras acciones se plasmaron en un informe dirigido a las autoridades provinciales (Rolandi et al. 2003). En el año 2004, el sitio fue incluido en el marco de un proyecto de arqueología y turismo cultural subsidiado por la Agencia Nacional de Promoción Científica y Tecnológica (ANPCYT) (Podestá y Rolandi 2005).

Luego de varios trabajos de campo se completó el registro de las representaciones y se elaboró una base de datos de los deterioros antrópicos que presenta la localidad (graffiti, impactos de bala, desprendimientos intencionales del soporte, fogones, etc.) producidos por las frecuentes visitas de cazadores y campistas. Esta documentación fue la base para el desarrollo de un plan de interpretación que incluyó la confección de una cartelería bilingüe y el diseño de un sendero interpretativo a fin de dar respuesta a la solicitud de la provincia de incluir la localidad en un circuito de turismo arqueológico. A pesar de los esfuerzos realizados, el plan propuesto y elevado a la provincia nunca fue puesto en práctica y hasta hoy la localidad no cuenta con protección alguna que frene las acciones vandálicas. Esta situación se agrava ante el avanzado proceso de deterioro natural que presentan los soportes con arte rupestre debido a las características intrínsecas de la roca soporte y a los agentes erosivos que actúan sobre la misma (Rolandi et al. 2009).

Cabe destacar que el sitio Los Colorados, situado a $20 \mathrm{~km}$ de esta localidad tiene representaciones, en parte, comparables a las de Palancho (Falchi y Torres 2010). En Los Colorados se realizó una recolección de superficie en la cual se recuperó material lítico y cerámico. El fechado por termoluminiscencia de un tiesto sin decoración dio como resultado 900+/-90 años AP (1105 DC) (UCTL1868) (INAPL 2009). Por otra parte, en 2004 se realizó un relevamiento del Cementerio Quebrada de Paluque, localizado a $16 \mathrm{~km}$ al Norte de

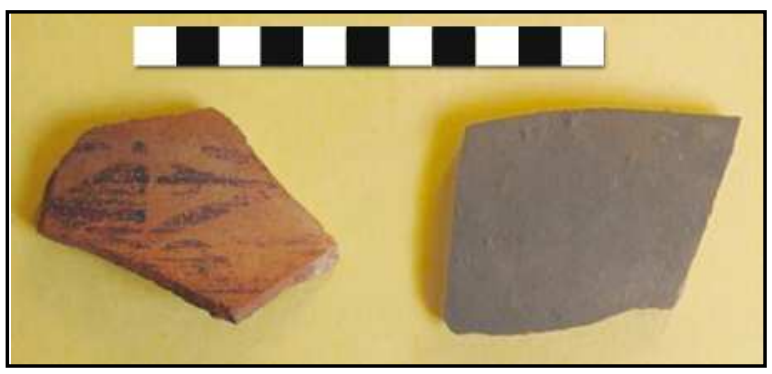

Figura 2. Izquierda tiesto cerámico del Cementerio Quebrada de Paluque. Derecha tiesto sin decoración de Los Colorados. La Rioja. 
Palancho, y se hizo una recolección de material disperso en superficie. El fechado por termoluminiscencia de un tiesto arrojó 990+/-100 años AP (1050 DC) (UCTL 1896) (Fig. 2).

\section{Ubicación y caracterización del área de estudio}

La localidad arqueológica con arte rupestre Palancho se encuentra en la zona donde las laderas occidentales de las Sierras de Velasco (Sierras Pampeanas) descienden hacia el Bajo de Carpintería, en el sur del departamento de Chilecito. Más específicamente, se ubica en uno de los extremos de la quebrada de Palanche, al suroeste del Bolsón de Paluqui, a 850 m.s.n.m. Se accede a la localidad desde la ruta 74, que une Patquia con Chilecito, donde se inicia un camino de tierra (antiguo Camino Real) que se abre en dirección Norte a lo largo de $22 \mathrm{~km}$. Luego de atravesar un tramo a campo traviesa, se alcanza la localidad (Fig. 1). Unos pocos kilómetros al Sudeste, más allá de la ciudad de Patquia, se extiende la región de Los Llanos, con altitudes promedio de 400 metros y clima riguroso.

La región se caracteriza por su aridez, el clima es cálido continental, con veranos muy calurosos e inviernos suaves. El área bajo estudio está comprendida dentro de la provincia biogeográfica del Monte (Cabrera y Willink 1973) que se caracteriza por presentar una vegetación homogénea con predominio del matorral, en la que se observan distintos tipos de jarilla (Larrea sp), retamo (Bulnesia retama), brea (Caesalpinia praecox) y cactáceas de los géneros Opuntia y Cereus, con ausencia de ejemplares arbóreos. En cuanto a la fauna, las especies presentes son representativas del distrito zoogeográfico subandino. Entre los camélidos, el guanaco (Lama guanicoe) es el más abundante y la presa preferida de los cazadores que frecuentan el lugar. Además, se puede destacar la presencia del ñandú y el cóndor entre las aves características.

La localidad arqueológica Palancho ocupa una superficie de ca. 28 ha. Está conformada por diez afloramientos muy erosionados de areniscas sedimentarias rojizas y bloques desprendidos, que se disponen en forma alineada y paralela con orientación NE-SO. La longitud de los afloramientos varía entre los 100 y $500 \mathrm{~m}$, salvo dos excepciones de aproximadamente $10 \mathrm{~m}$ de largo. Entre los afloramientos hay bloques con morteros pero, curiosamente, no se han hallado otros vestigios arqueológicos en superficie. Esta ausencia puede explicarse, en parte, por el efecto de las aguas de las lluvias de primavera-verano que bajan de la Sierra de Velasco y que corren entre los afloramientos produciendo el arrastre de materiales y profundas cárcavas (Fig. 3). En la actualidad la fuente de agua permanente más cercana se ubica a unos $4 \mathrm{~km}$. de distancia, en una posta abandonada (Casa de Estado) del antiguo Camino Real que unía Patquía con Chilecito. Si bien no se cuenta con información paleoambiental, este dato es significativo ya que apunta a la imposibilidad de un asentamiento a largo plazo en las inmediaciones de la localidad arqueológica.

\section{Arte rupestre}

Soportes, distribución y cantidad de motivos

Una de las características relevantes de Palancho es la monumentalidad de su emplazamiento. Los relieves de los afloramientos de arenisca utilizados como soportes para la ejecución del arte rupestre sobresalen con su color rojizo dentro del paisaje llano dominante con un fondo recortado por la silueta de la Sierra de Velasco (Fig. 3). 


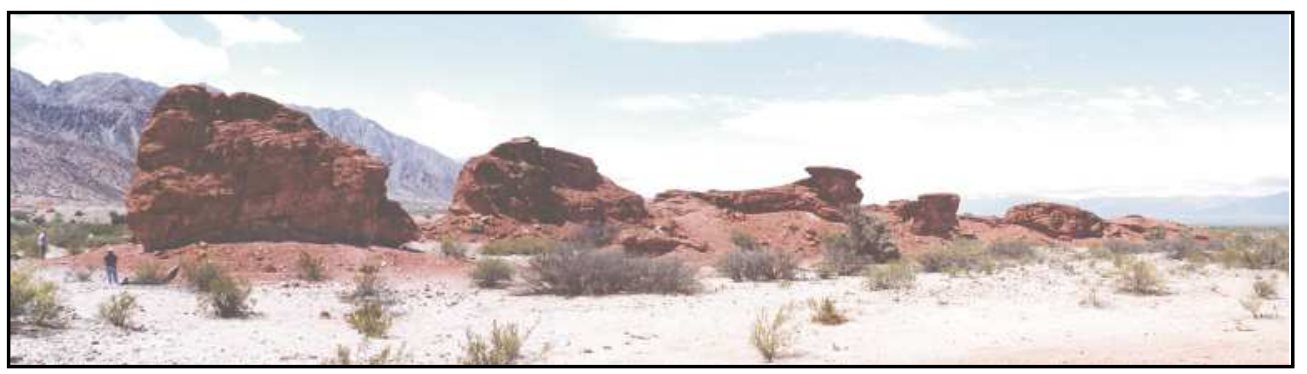

Figura 3. Afloramiento de arenisca de la localidad arqueológica Palancho con el fondo de la Sierra de Velasco, La Rioja.

Los soportes seleccionados para el arte rupestre fueron, además de las paredes de los afloramientos de arenisca, los bloques caídos al pié. También se han registrado grabados en el piso de roca expuesta en sectores planos de algunas cumbres de ciertos afloramientos $y$, un único caso, en un sector de techo de un pequeño alero. Los afloramientos (Af.) se presentan como una acumulación estratificada y diaclasada compuestos por un material con poca resistencia a los agentes erosivos, por lo que las manifestaciones rupestres grabadas están en un proceso de desgaste acelerado, tanto por caída del soporte como por el producido por la erosión eólica que va puliendo la superficie rocosa restando visibilidad a los grabados. El producto del desgaste de la roca -arenas rojizas y rocas de distintas dimensiones- se va acumulando al pie de los afloramientos conformando terraplenes que en algunos sectores adquieren una pronunciada pendiente (Fig. 3).

El arte rupestre se documentó en las diferentes caras de los afloramientos 2, 3, 4, 5, 6, 7, 8 y 10, cubriendo una totalidad de 59 paredes, 58 bloques, 4 cumbres y un sector de techo (Tabla 1). La unidad topográfica que se define como "pared" tiene superficies de tamaños muy diversos que varían entre los 0,32 y $20 \mathrm{~m} 2$. En algunos casos los grabados se observan en paredes a grandes alturas (por ej. en el Af. 7, Pared 7 a más de $10 \mathrm{~m}$ de altura), en otros se ubican a pocos centímetros del suelo. La distribución de las representaciones en los diferentes afloramientos es muy irregular, siendo los más densamente utilizados los números 6 y 7 , en los cuales se registraron casi la totalidad de las superposiciones de motivos.

Con el objetivo de ordenar este universo tan vasto de representaciones se tomaron en cuenta las siguientes variables de análisis: tipos de motivos, técnicas de ejecución, tratamiento de la forma, grados de pátina (relativa en cada unidad topográfica) y superposiciones de motivos.

\begin{tabular}{|l|l|l|}
\hline No Afloramiento & $\begin{array}{l}\text { Cantidad de } \\
\text { motivos }\end{array}$ & Superposiciones \\
\hline AF2 & 1 & - \\
\hline AF3 & 17 & - \\
\hline AF4 & 18 & - \\
\hline AF5 & 52 & 1 \\
\hline AF6 & 292 & 18 \\
\hline AF7 & 488 & 29 \\
\hline AF8 & 1 & - \\
\hline AF10 & 5 & - \\
\hline Total general & 874 & 48 \\
\hline
\end{tabular}

Tabla 1. Total de motivos y superposiciones por afloramiento. 
Características morfológicas y técnicas

Los 874 motivos registrados se agruparon, según sus características morfológicas, en tres categorías: abstractos (N: 529, 60,53\%), figurativos (N: 315, 36,04\%) e indeterminados por deterioro del soporte (N: 30, 3,43\%) (Fig. 4).

Entre los motivos abstractos (32 tipos) se destacan: línea quebrada (13,61\% del total de motivos abstractos), líneas paralelas, línea sinuosa, círculo con línea, enmarcado y línea recta. Entre los menos representados se incluyen: figura escalonada, línea curva, círculo/s, geométrico complejo. El listado completo de motivos y sus correspondientes números totales y porcentajes pueden consultarse en las Figuras 5 y 6 y en la Tabla 2.

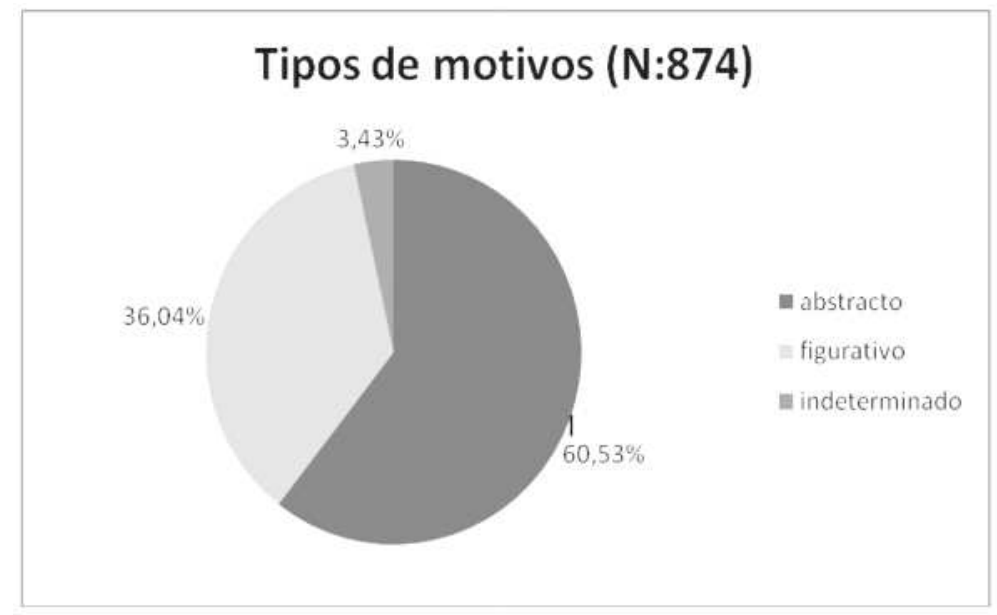

Figura 4. Porcentaje de tipos de motivos.

Dentro de los figurativos, se diferenciaron 20 tipos, entre los que se destacan por su mayor frecuencia: tridígitos (26,03\% del total de figurativos), pisadas humanas $(24,76 \%)$ y pisadas de felino (12,70\%). En menores cantidades están: camélidos, zoomorfos no identificados, figuras humanas y suris, seguidos por tipos de motivos de muy baja frecuencia, como por ejemplo: cabeza trofeo, rostro humano, lagartija, serpentiforme y rastros de suri, camélido y humano (Fig. 5 y 7 , Tabla 3).

Cabe aclarar que dentro de algunos tipos de motivos figurativos se detecta una amplia variabilidad morfológica de la cual sólo mencionaremos algunos ejemplos a medida en que se detallen los cambios que se observan a lo largo de la secuencia de producción de grabados establecida para la localidad, tema que se tratará más adelante.

Con respecto a las técnicas de ejecución, el arte rupestre de Palancho presenta únicamente motivos grabados ejecutados a través de una gran diversidad de técnicas: picado, incisión, horadado, abrasión y raspado, y las combinadas: inciso/abradido, picado/abradido, y picado/inciso (Fig. 8). Para esta categorización conviene aclarar que en este trabajo se distingue el raspado del abradido. El raspado aquí se considera una abrasión superficial, en cambio el abradido supone la acción reiterada de raspado dando como resultado surcos más profundos de contornos más definidos. El horadado supone un movimiento rotacional del instrumento para obtener un hoyo circular en el soporte (Fiore 2007). 


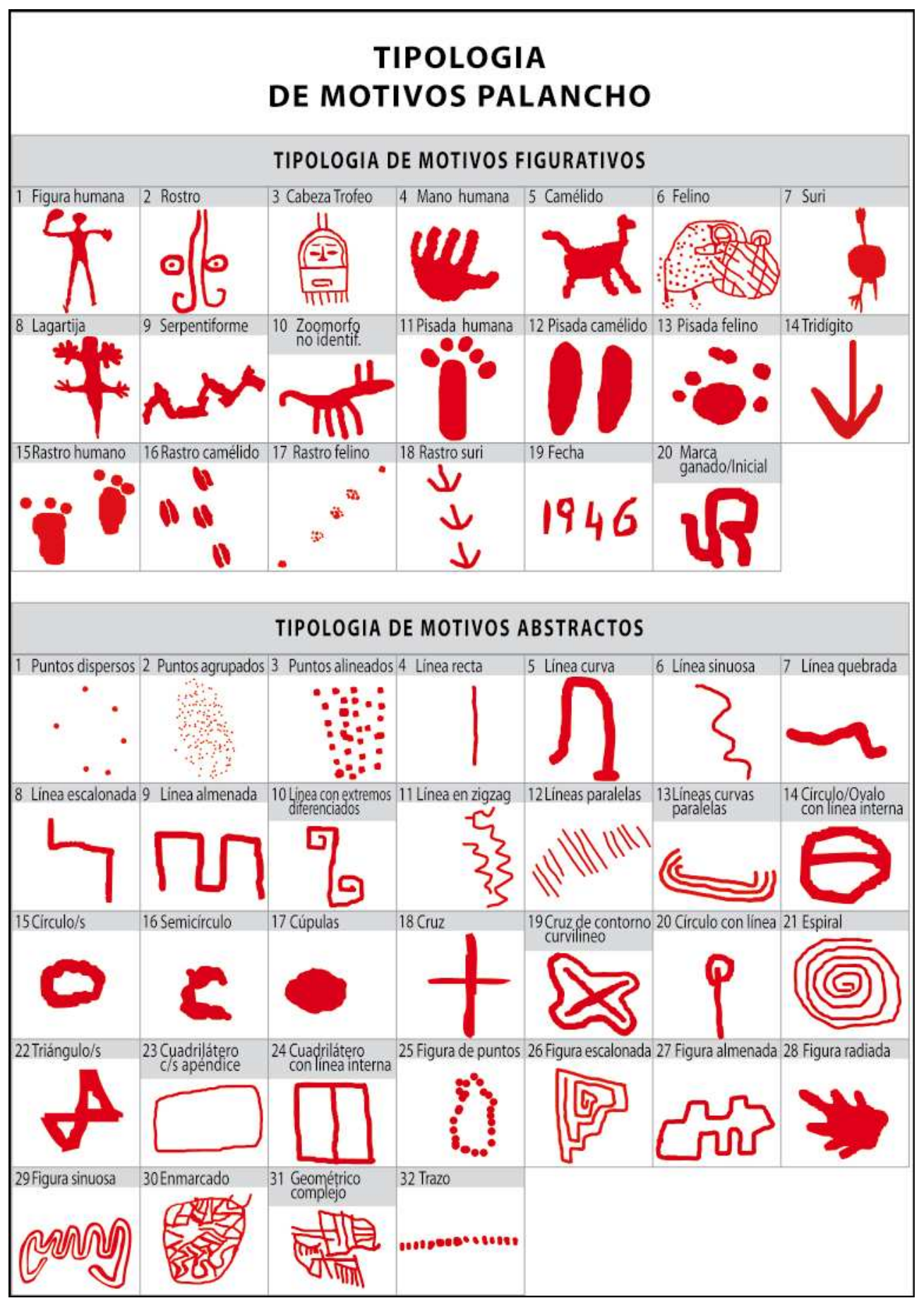

Figura 5. Cuadro tipológico. 


\begin{tabular}{|l|r|r|}
\hline \multicolumn{1}{|c|}{$\begin{array}{c}\text { Tipos de motivos } \\
\text { abstractos }\end{array}$} & \multicolumn{1}{c|}{ N } & \multicolumn{1}{c|}{} \\
\hline puntos dispersos & 4 & $0,76 \%$ \\
puntos agrupados & 9 & $1,70 \%$ \\
puntos alineados & 6 & $1,13 \%$ \\
línea recta & 38 & $7,18 \%$ \\
línea curva & 23 & $4,35 \%$ \\
línea sinuosa & 41 & $7,75 \%$ \\
línea quebrada & 72 & $13,61 \%$ \\
línea escalonada & 15 & $2,84 \%$ \\
línea almenada & 6 & $1,13 \%$ \\
línea con extr. difer. & 10 & $1,89 \%$ \\
línea en zigzag & 18 & $3,40 \%$ \\
líneas paralelas & 53 & $10,02 \%$ \\
líneas curvas paralelas & 3 & $0,57 \%$ \\
círc./óvalo c/línea interna & 8 & $1,51 \%$ \\
círculo & 22 & $4,16 \%$ \\
semicírculo & 6 & $1,13 \%$ \\
cúpula & 16 & $3,02 \%$ \\
cruz & 8 & $1,51 \%$ \\
cruz de cont. curvilíneo & 6 & $1,13 \%$ \\
círculo c/ línea & 41 & $7,75 \%$ \\
espiral & 4 & $0,76 \%$ \\
triángulo & 5 & $0,95 \%$ \\
cuad. con/sin apéndice & 6 & $1,13 \%$ \\
cuad. c/ línea interna & 3 & $0,57 \%$ \\
figura de puntos & 5 & $0,95 \%$ \\
figura escalonada & 24 & $4,54 \%$ \\
figura almenada & 6 & $1,13 \%$ \\
figura radiada & 2 & $0,38 \%$ \\
figura sinuosa & 9 & $1,70 \%$ \\
enmarcado & 36 & $6,81 \%$ \\
geométrico complejo & 20 & $3,78 \%$ \\
trazos & 4 & $0,76 \%$ \\
\hline TOTAL & 529 & $100,00 \%$ \\
\hline
\end{tabular}

Tabla 2. Motivos abstractos, cantidades y porcentajes. Referencias: extr.difer.: extremos diferenciados; circ.: círculo; c/: con; cont.: contorno; cuad.: cuadrilátero.
La técnica más empleada es el picado con 467 casos. Siguen en número decreciente el abradido (N: 140), el picado/abradido $(\mathrm{N}: 94)$, el inciso $(\mathrm{N}: 72)$, el raspado $(\mathrm{N}$ : 27), el picado/inciso (N: 7), el abradido/ inciso $(\mathrm{N}: 2) \mathrm{y}$, por último, el horadado $(\mathrm{N}$ : 7). Esta última técnica se presenta como complemento de otras y es especialmente utilizada durante un momento de la secuencia de grabados de la localidad (Grupo 2), como se verá más adelante. En 58 casos no se ha podido definir la técnica de ejecución. Se trata de grabados localizados a gran altura y que resultan inaccesibles para realizar un relevamiento adecuado (por ejemplo Af. 7, Pared 7) (Fig. 8).

Indicadores temporales: superposiciones, reciclados y pátinas

Las superposiciones de motivos registradas (47 casos en los afloramientos 6 y 7 y una sola en el 5) dan cuenta de la reutilización de determinados afloramientos (Tabla 1). En muchos casos sugerimos que las superposiciones no son azarosas y que, por lo contrario, hay una búsqueda en superponer o yuxtaponer intencionalmente representaciones sobre o en proximidad a otras preexistentes. Los casos de reciclados documentados también llevan a constatar que algunos soportes son reutilizados expresamente a lo largo de la secuencia de producción de los grabados en la localidad. Esta reutilización de soportes, en desmedro del uso de soportes libres -que vale aclarar son abundantes en la localidadse refleja también en la alta densidad de representaciones que se registra en algunas unidades topográficas (pared o bloque). Por ejemplo en el Af. 6 la Pared 4B, que tiene una superficie de $8,55 \mathrm{~m} 2$, fueron contabilizados

75 motivos simples y compuestos con un total 160 elementos, es decir 18,71 representaciones (o elementos) por $\mathrm{m} 2$.

Las diferencias de coloración de las pátinas de las superficies grabadas son notables en Palancho. Si bien reconocemos que la conformación de pátinas puede responder a diferentes causas, en el caso de Palancho marcan una diferenciación temporal y en todos los casos se ha considerado su valor cronológico en relación a otras variables. Se diferenciaron tres grados de 


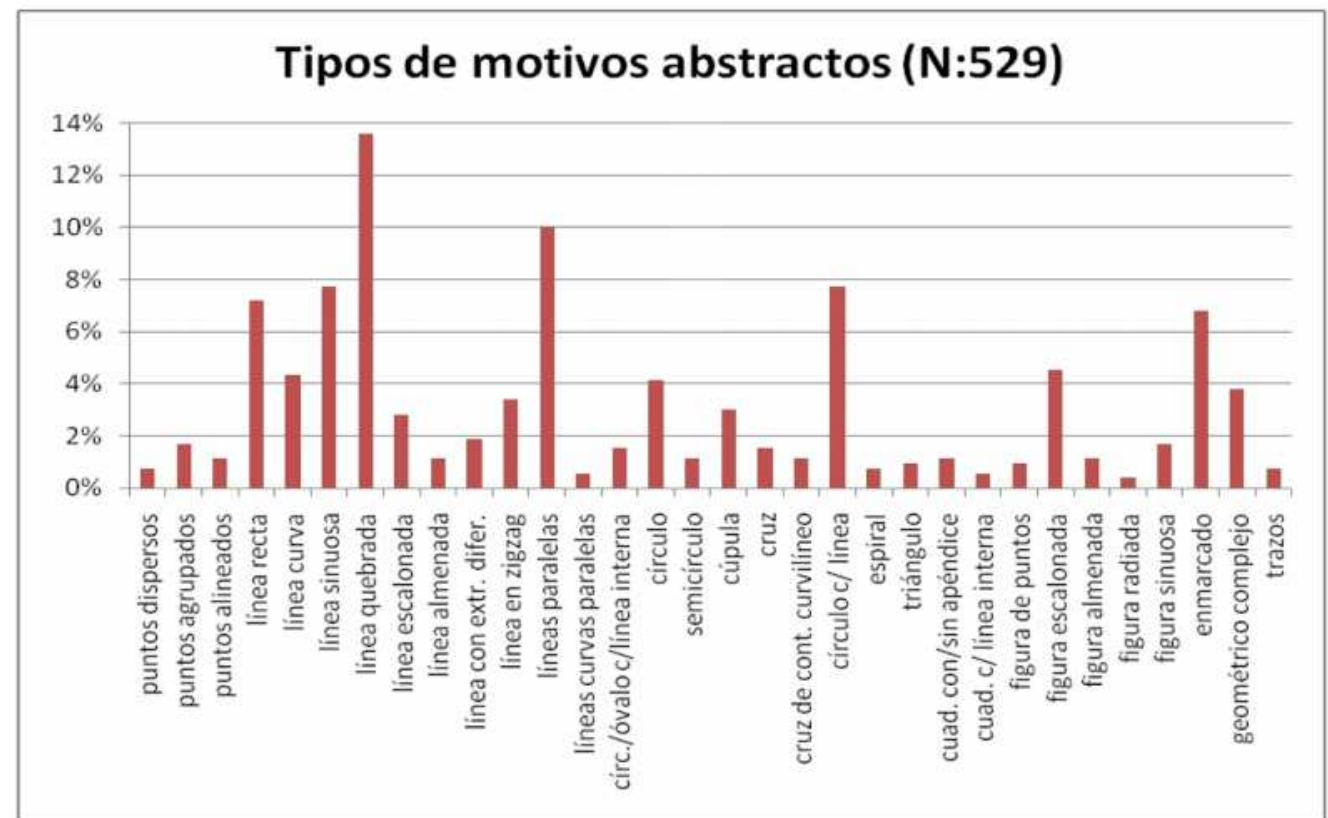

Figura 6. Motivos abstractos, porcentajes.

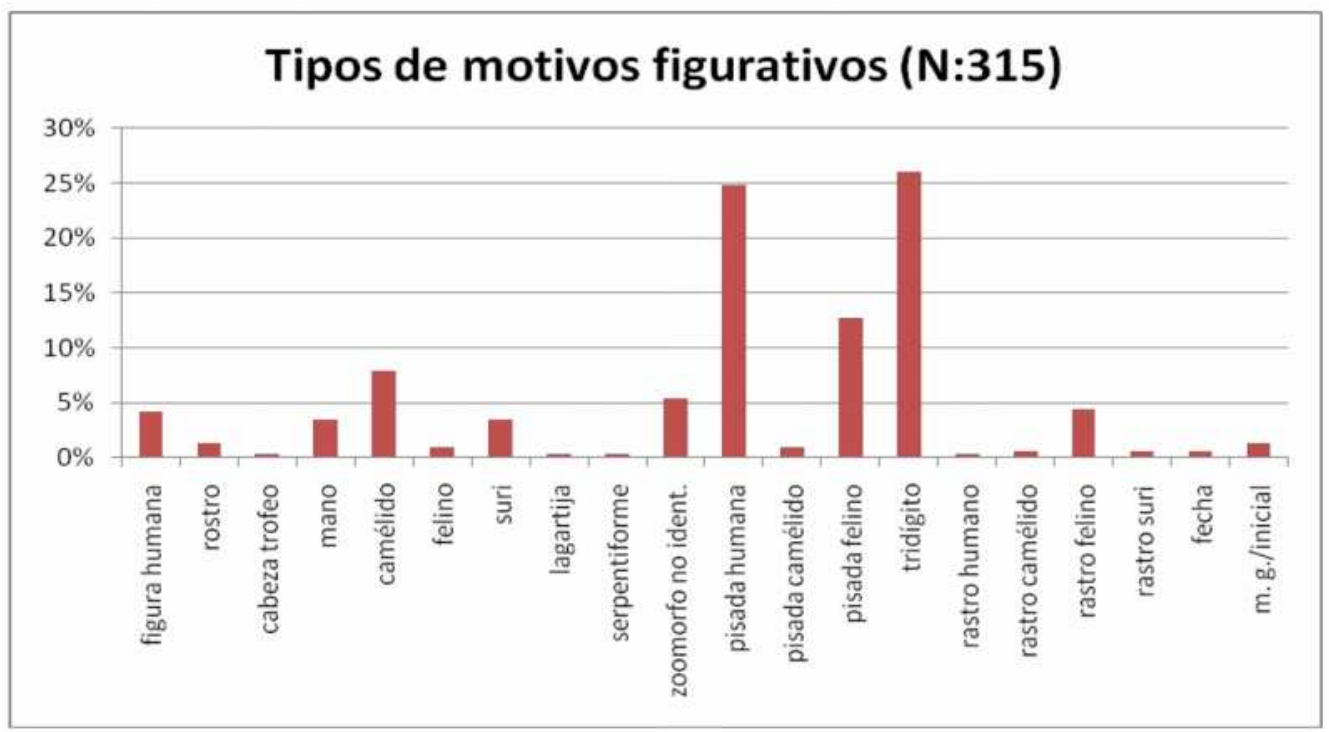

Figura 7. Motivos figurativos, porcentajes.

pátina, la 1 es la de coloración más fuerte, de formación más antigua y poco contrastante con el soporte circundante, de tono rojizo. En el otro extremo, están los grabados de pátina 3 de tonalidad clara y contrastante con la roca soporte, como es el caso de los motivos históricos que se analizarán más adelante.

\section{Secuencia temporal del arte de Palancho: grupos y asignación estilística}

En base a los tipos de motivos, las técnicas de ejecución y teniendo en cuenta sobre todo los casos de superposiciones de motivos registrados y las variaciones en la coloración 


\begin{tabular}{|l|r|r|}
\hline \multicolumn{1}{|c|}{$\begin{array}{c}\text { Tipos de motivos } \\
\text { figurativos }\end{array}$} & $\mathrm{N}$ & \multicolumn{1}{c|}{$\%$} \\
\hline figura humana & 13 & $4,13 \%$ \\
rostro & 4 & $1,27 \%$ \\
cabeza trofeo & 1 & $0,32 \%$ \\
mano & 11 & $3,49 \%$ \\
camélido & 25 & $7,94 \%$ \\
felino & 3 & $0,95 \%$ \\
suri & 11 & $3,49 \%$ \\
lagartija & 1 & $0,32 \%$ \\
serpentiforme & 1 & $0,32 \%$ \\
zoomorfo no ident. & 17 & $5,40 \%$ \\
pisada humana & 78 & $24,76 \%$ \\
pisada camélido & 3 & $0,95 \%$ \\
pisada felino & 40 & $12,70 \%$ \\
tridígito & 82 & $26,03 \%$ \\
rastro humano & 1 & $0,32 \%$ \\
rastro camélido & 2 & $0,63 \%$ \\
rastro felino & 14 & $4,44 \%$ \\
rastro suri & 2 & $0,63 \%$ \\
fecha & 2 & $0,63 \%$ \\
m. g./inicial & 4 & $1,27 \%$ \\
\hline TOTAL & 315 & $100,00 \%$ \\
\hline Tabla 3. Motivos figur
\end{tabular}

Tabla 3. Motivos figurativos, cantidades y porcentajes. Referencias: ident.: identificado; m.g.: marca de ganado. de las pátinas, se elaboró una secuencia de producción de grabados en la localidad.

Aproximadamente el $60 \%$ de los motivos de la localidad fue asignado a cinco grupos ordenados secuencialmente entre el de ejecución más temprana (Grupo 1) y el de menor antigüedad (Grupo 5), si bien hay que aclarar que un $6,30 \%$ de 1 os mismos son de asignación dudosa. El resto de los motivos $(39,47 \%)$ permanece sin asignación alguna destacando, por esta razón, el carácter tentativo de estas agrupaciones. Las representaciones de algunos de estos grupos guardan estrechas similitudes temáticas y estilísticas con otros conjuntos de arte rupestre y de iconografía cerámica y textil del Noroeste Argentina (NOA) y del área Centro-Oeste que se señalarán en los casos en que corresponda.

\section{Grupo 1}

Este grupo es el que reúne la mayor cantidad de los motivos de la localidad (N: 239 y 24 dudosos), registrándose 39 tipos que se distribuyen en todos los afloramientos con excepción del Af. 8 (con un solo motivo no asignado) (Tabla 4).

Se incluyen: motivos de pisadas y rastros (felino, camélido, suri, humana), manos,

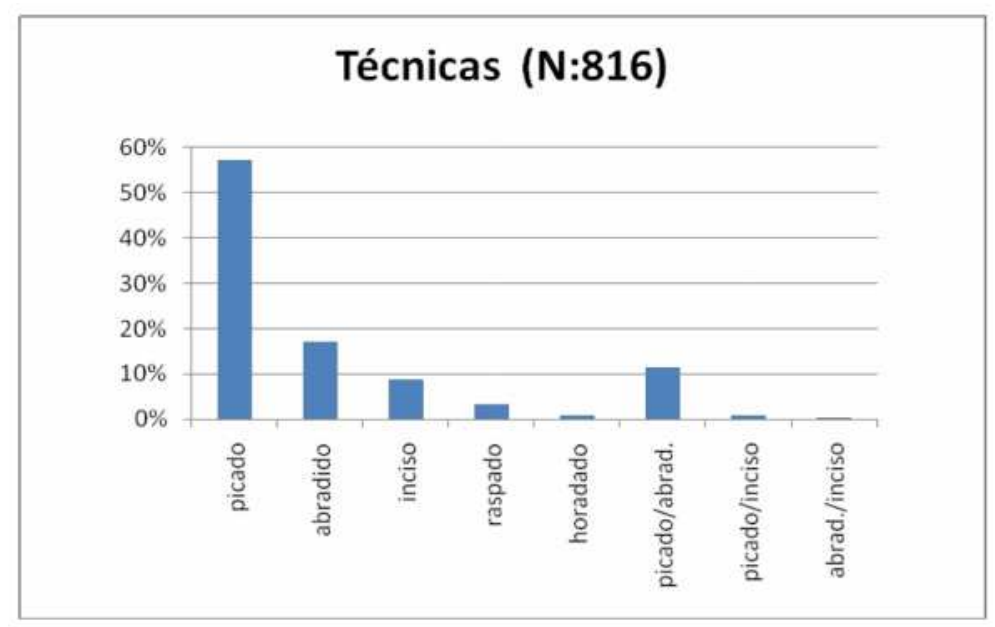

Figura 8.Técnicas de grabados, porcentajes. Referencia: abrad.: abradido. 


\begin{tabular}{|l|l|l|l|l|l|l|l|l|}
\hline $\begin{array}{l}\text { Afloramientos/ } \\
\text { Grupo }\end{array}$ & AF2 & AF3 & AF4 & AF5 & AF6 & AF7 & AF8 & AF10 \\
\hline Grupo 1 & X & X & X & X & X & X & & X \\
\hline Grupo 2 & & & X & & X & X & & X \\
\hline Grupo 3 & & & & & X & X & & \\
\hline Grupo 4 & & & X & X & X & X & & \\
\hline Grupo 5 & & & & & $X$ & X & & \\
\hline
\end{tabular}

Tabla 4. Distribución de los grupos por afloramiento.

figuras humanas, camélidos, suris, zoomorfos no identificados, cruces de contorno curvilíneo, líneas rectas, paralelas, quebradas, sinuosas, curvas, en zigzag, escalonadas y con extremos diferenciados, espiral, enmarcados, figuras escalonadas y almenadas, geométricos simples (semicírculos, círculos, círculo con línea, cuadrilátero) y figuras geométricas complejas. También se destacan los puntos alineados y agrupados. Las cúpulas son exclusivas de este grupo (Fig. 5).

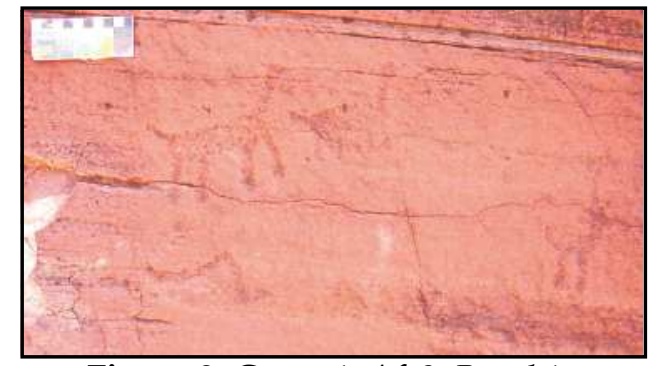

Figura 9. Grupo 1. Af. 3, Pared 1.

Camélidos alineados y suri ejecutados por picado discontinuo. Pátina 1. Camélido izquierda: $15 \mathrm{~cm}$ de largo.

Los siete motivos de camélidos se caracterizan por la representación del cuerpo con tratamiento plano, cuatro patas y, en la mayoría de los casos, orejas, todos rasgos que los distinguen del mismo tipo de figuras de grupos de motivos ejecutados más tardíamente (Grupo 2). En la mayor parte de los casos se representa un solo animal y sólo en dos ejemplos aparece un par de camélidos alineados (Fig. 9).

Las representaciones de figuras humanas de la localidad son exclusivas de este grupo, con excepción de una asignada al Grupo 2 y otra figura que permanece sin agrupación. Las diez representaciones de este grupo siempre se presentan de frente, en la mayoría de los casos con los brazos en alto y/o portando objetos (Fig. 10). Los motivos de pisadas humanas (27 motivos) y de animales también son cuantitativamente importantes, sin ser exclusivos de este grupo ya que en los Grupos 2 y 3 también se registra su presencia.

Uno de los motivos que se destaca en el conjunto de representaciones abstractas es la línea escalonada que, en algunos casos, forma figuras de pirámides. Las cruces de contorno curvilíneo son también representativas y exclusivas de este grupo si bien, de los seis casos documentados, dos son de asignación dudosa.

Los grabados se caracterizan por la utilización de la técnica de picado regular discontinuo (que deja sectores del soporte sin remover). Las figuras son de tratamiento lineal y plano y la coloración de la pátina es oscura (pátina 1) por lo que, en general, contrastan levemente con el soporte circundante (Fig. 9). Ambos rasgos (picado discontinuo y pátina oscura) permiten que estos grabados sean asignados fácilmente al primer grupo de ejecución de la localidad, característica que no se repite en los grupos subsiguientes ya que su agrupación ha sido más dificultosa, con excepción del Grupo 5. En los casos de superposiciones, los 


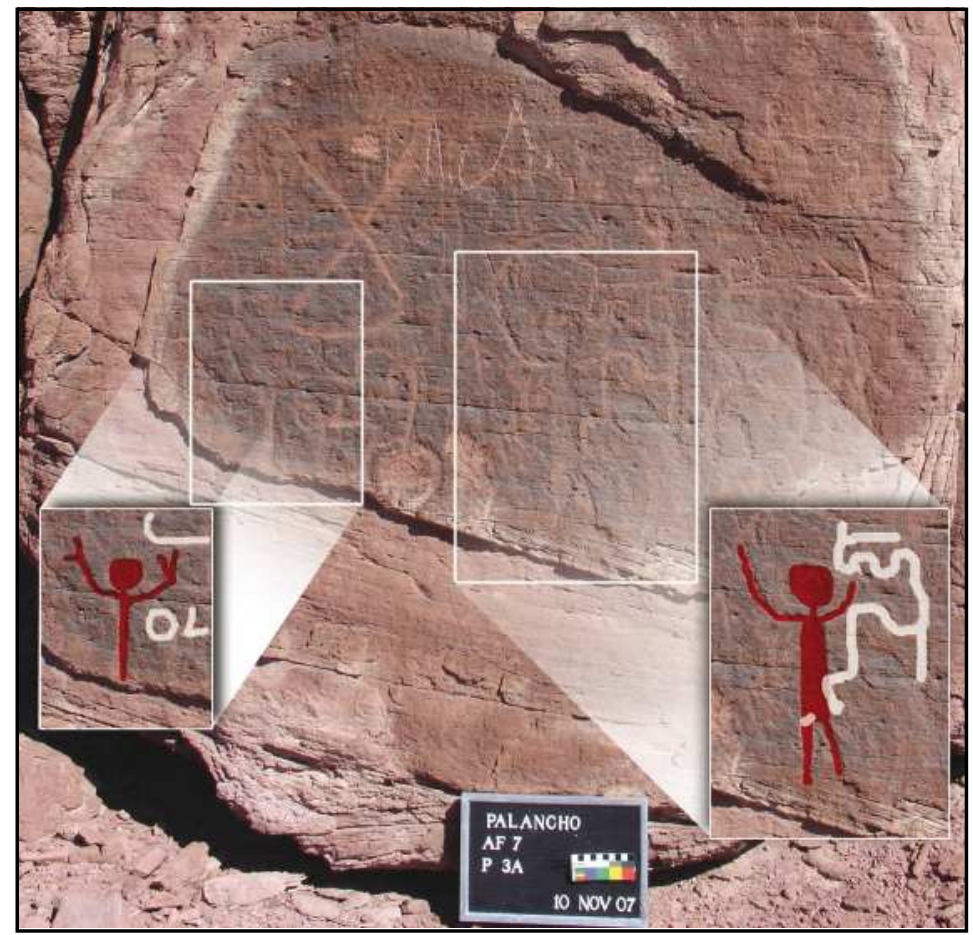

Figura 10. Grupo 1. Af. 7, Pared 3A. Figuras humanas y superposiciones del Grupo 2 (color claro) sobre el 1 (color oscuro).

motivos de este grupo están siempre por debajo. Existen 15 superposiciones de motivos de los grupos 2, 3 y 4 sobre el 1.

La asignación del Grupo 1 se torna compleja por la falta de trabajos comparativos. Parte del repertorio iconográfico del Grupo 1 fue registrado en el Parque Nacional Talampaya (Schobinger 1966; Giordano y Gonaldi 1991 y Ferraro 2005) y región de Los Llanos (Cáceres Freyre 1956) en La Rioja y en el Parque Provincial Ischigualasto en San Juan (Re et al. 2009 y en este volumen). Asimismo, la cruz de contorno curvilíneo, que es exclusiva de este grupo, si bien es un motivo de gran dispersión geográfica y amplitud temporal, acompaña a las pirámides, las líneas escalonadas y a los motivos de pisadas en el Parque Nacional Talampaya y en el Parque Provincial Ischigualasto. Cabe mencionar que algunos tipos que integran en forma exclusiva el Grupo 1 en Palancho, principalmente las cruces de contorno curvilíneo, las figuras humanas y las cúpulas, entre otros motivos que también participan del repertorio de los grupos restantes, se encuentran en soportes de Ischigualasto y de la Sierra de Valle Fértil. En dos sitios (LT y PQC) localizados en esta última, los soportes se asocian con círculos de piedras de colores y áreas con morteros, propios de sitios de actividades múltiples asignados al Período Medio o de Integración en base a la presencia de cerámica decorada de estilo "La Aguada" y a la existencia de dos fechados obtenidos por termoluminiscencia indicativos de esos momentos de ocupación (Guraieb et al. 2010; Re et al. 2009). 


\section{Grupo 2}

Este Grupo incluye 106 motivos y 13 de asignación dudosa que se ordenaron en 33 tipos. El repertorio antropomorfo contiene el único caso de figura humana que no pertenece al Grupo 1 y una cabeza trofeo (exclusiva del grupo), además de pisadas humanas. Existen también pisadas de suri (tridígitos) y de camélidos. Entre los zoomorfos predominan los felinos y camélidos, y entre los abstractos los geométricos curvilíneos como espirales, líneas curvas paralelas, líneas paralelas y enmarcados con contorno rectilíneo o curvilíneo y elementos geométricos en el interior (Fig. 5).

La representación de figura humana (Af.7- Pared 7) es sumamente indicativa en la definición de este grupo. La misma está compuesta por una cabeza-máscara de contorno oval, ojos oblicuos al eje de la nariz y de forma en "grano de café", el cuerpo -separado de la cabeza- es cuadrangular con puntos internos. Estos puntos, ejecutados por horadado, sobrepasan el contorno del cuerpo en la parte superior del mismo. Hacia arriba y a la izquierda del observador se encuentra representada una mano y por debajo del cuerpo, dos pequeños pies. Todas las partes están separadas entre sí y solo una visión de conjunto permite reconocer la figura humana en su totalidad (Fig. 11).

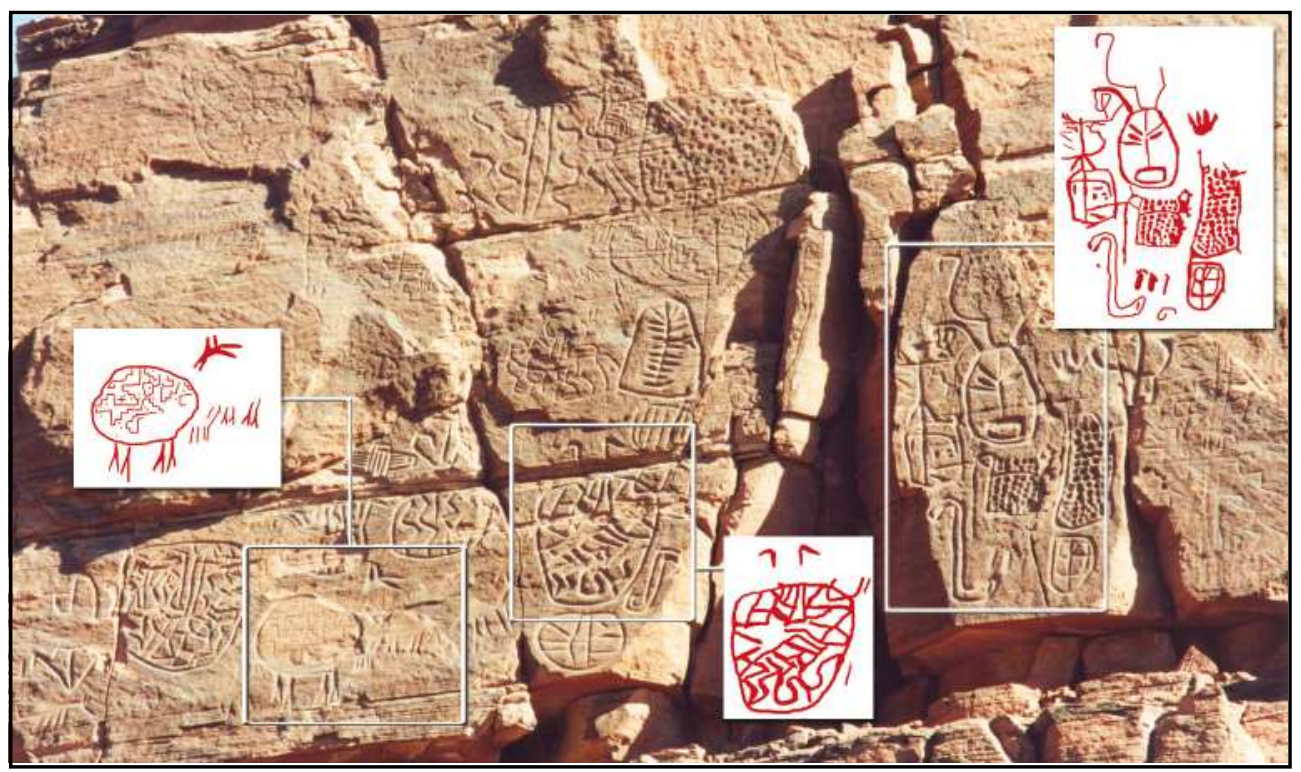

Figura 11. Grupo 2. Af. 7, Pared 7. Figura humana, camélidos y enmarcados con elementos geométricos en el interior. Pared a gran altura, sin indicación de escala.

Las tres figuras de felinos de Palancho son también privativas de este grupo. Están diseñadas con el cuerpo de perfil y la cabeza de frente con orejas redondeadas. El cuerpo, al igual que la figura humana antes descripta, se halla cubierto de puntos horadados a manera de las típicas manchas de la piel del felino. Las cuatro extremidades terminan con la indicación de la pisada de este animal, tal como es hallada frecuentemente en forma aislada o conformando rastros. Las imágenes del felino suelen encontrarse dominando la superficie de los bloques, único soporte utilizado para la representación de estos animales (Fig. 12). 


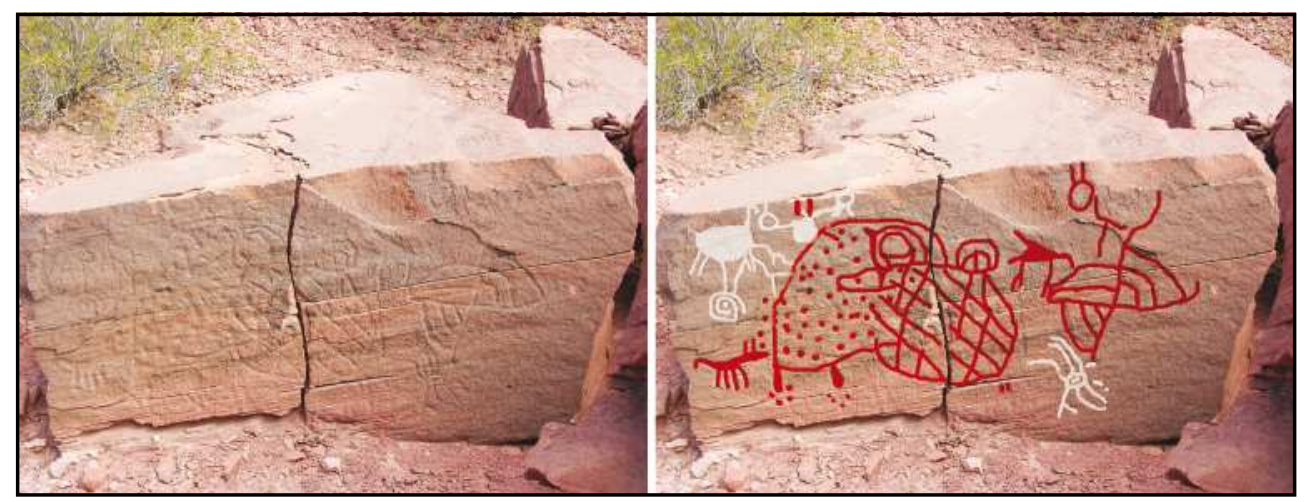

Figura 12. Grupo 2. Af. 7, Bloque 15. Figura de felino y otros motivos (color oscuro) superpuestos a grabados del Grupo 1 (color claro). Felino: $70 \mathrm{~cm}$ de largo.

El diseño de los camélidos es exclusivo también de este grupo y se diferencia claramente del descripto para el Grupo 1. Los animales se representan con cuerpo oval alisado y patas, cuello y cabeza ejecutados a través de un surco profundo. Las patas finalizan con dos líneas bifurcadas en V (Fig. 11).

Entre los abstractos, se destacan los enmarcados de contorno rectilíneo o curvilíneo con una gran diversidad de elementos geométricos en el interior dispuestos en forma caótica sin guardar relaciones de simetría. Buenos ejemplos son los motivos del Af. 7, Pared 7, donde se da la mayor profusión de enmarcados de este tipo. Los elementos internos no se repiten en ningún caso, rasgo que otorga un carácter exclusivo a cada uno de los enmarcados. Si bien este tipo de motivo no es privativo de este grupo, aquí adquiere mayor complejidad y diversidad morfológica (Fig. 11).

Este grupo se distribuye en la localidad en forma más restringida en su comparación con el Grupo 1, hallándose presente en los afloramientos 4, 6, 7 y 10 (Tabla 4). En ocasiones se halla ejecutado en soportes a gran altura (a más de diez metros) como es el caso del Af. 7- Pared. 7 (Fig. 11). Se registran al menos cuatro superposiciones de motivos del Grupo 3 y 4 sobre otros del Grupo 2. Es interesante señalar un caso de reciclado de un camélido del Grupo 2 cuyo cuerpo es abradido y grabado en el interior con motivos escalonados, típicos del Grupo 4 (Fig. 11). Los grabados presentan pátina 2.

Buena parte del arte rupestre del Grupo 2 puede relacionarse con la estilística de La Aguada. Dentro del ámbito que nos ocupa (sector meridional de la dispersión de La Aguada en el NOA), ésta tiene un amplio rango temporal (ca. 600-1300 d.C.), según las investigaciones dirigidas por Callegari y su equipo (Callegari et al. 2009, entre otros). En Palancho no puede señalarse la existencia de un arte Aguada, con las características del de la Sierra de Ancasti (Catamarca) (de la Fuente et al. 1979). La imagen del sacrificador, que define la estilística Aguada más al Norte no está presente en Palancho, pero sí es posible reconocer aquí algunas imágenes y rasgos de diseño que remiten a esa ella. Uno de los ejemplos más ilustrativos es la figura humana descripta anteriormente (Fig. 11). Es posible destacar que la representación del rostro de esta figura es también recurrente en otros ámbitos que, al igual que Palancho, son periféricos al radio central de acción de La Aguada (región de Ancasti y La Candelaria en Catamarca). Buen ejemplo de lo antedicho es la presencia de rostros-máscaras con rasgos típicamente Aguada en sitios de la Puna catamarqueña (Punta del Pueblo en Antofagasta de 
la Sierra y Potrerito 1 en el bolsón de Laguna Blanca) (Podestá 1989; Aschero 1999; Podestá et al. 2005). Otros casos han sido reportados en el Oeste de la provincia de La Rioja, en sitios próximos a la localidad de Villa Castelli (Sierra de Famatina) (Callegari 2001; Callegari et al. 2009). También puede mencionarse el mascariforme del Parque Nacional Talampaya, citado por Schobinger. El autor destaca la presencia de alfarería Aguada en recintos próximos a las paredes con grabados rupestres (Schobinger 1966). La cabeza trofeo, representada de frente con prolongaciones inferiores, que aparece junto a un suri de cuerpo en espiral, es también un claro ejemplo de imaginería Aguada (Fig. 13).

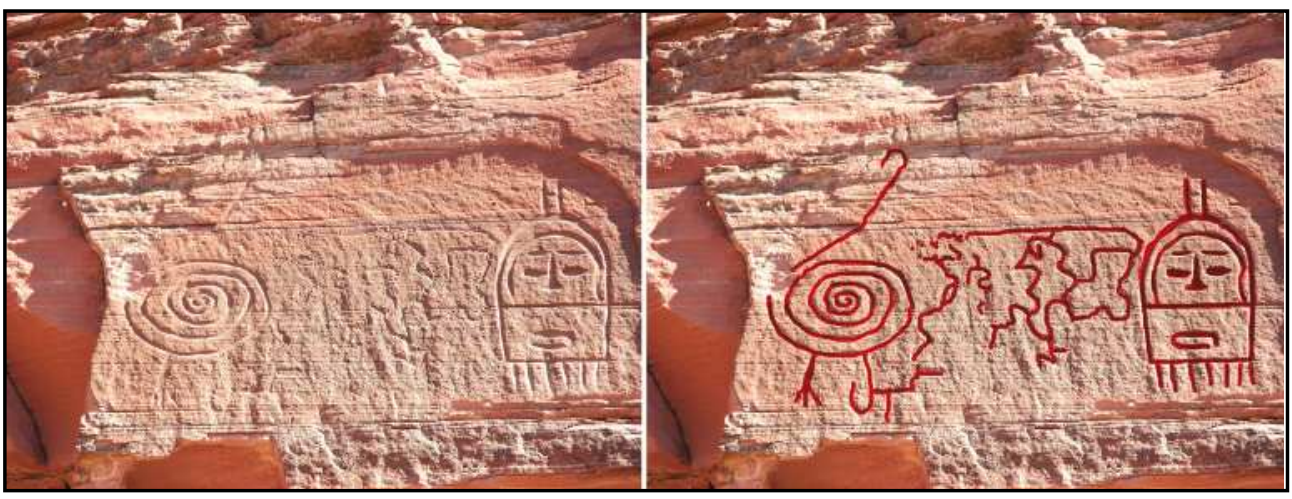

Figura 13. Grupo 2. Af. 7, Pared 14. Suri con cuerpo en espiral y cabeza trofeo.

Las tres figuras de felinos, representadas con cuerpo completo remiten también al arte Aguada, si bien en ningún caso se identificaron fauces y otros rasgos típicos de este animal que suelen presentarse en forma aislada en otros componentes estilísticos del mismo (ver al respecto ejemplos reportados por Callegari y su equipo en el Oeste riojano antes citados y por Gordillo et al. 2000 en Catamarca y Norte de La Rioja). La escasa imaginería Aguada reconocida en el arte rupestre de Antofagasta de la Sierra (Puna catamarqueña) presenta también casos de felinos con representaciones de "pisadas" en el extremo de las patas como ocurre en Palancho (Podestá 1989:46).

Con respecto a los motivos enmarcados con elementos geométricos internos que acompañan estas figuras, se han identificado similares en el sitio El Salado (Finca San Isidro) en la Sierra de Malanzán, próximo a la Reserva Provincial de Uso Múltiple Guasamayo en los Llanos riojanos (Torres y Zubeldía 2007) (Fig.1). Más alejado de nuestra región de estudio, Callegari (2001) describe la presencia de motivos geométricos curvilíneos (círculos vacíos, círculos con puntos en interior, espirales, etc.) y rectilíneos (líneas rectas, líneas zigzagueantes, rectángulos vacíos y con el interior dividido, entre otros) como característicos de uno de los sitios del Oeste riojano (Rincón del Toro) y frecuentes en la decoración alfarera Aguada del área (Callegari 2001:28). Los motivos de círculos con punto central son descriptos también en una pieza textil Aguada recuperada en el sitio Punta del Barro, valle de Iglesia (San Juan) que son comparados con diseños similares propios de la cerámica pintada (Michieli 2001a:33). El Grupo 2 de Palancho presenta varios motivos geométricos simples de los tipos descriptos. En una comparación interregional, encontramos algunos puntos de coincidencia con el arte rupestre del Norte Semiárido chileno (Troncoso et al. 2008). Para el caso de los motivos enmarcados, se señalan semejanzas estilísticas con las "representaciones a partir de un marco" analizadas por Cabello (2011) ubicadas en el Valle de Chalinga (Provincia del Choapa), propias del tradicional estilo Limarí. Esta autora describe el desarrollo de dichas 
representaciones a lo largo del tiempo: desde el reconocimiento de un motivo figurativo que alude al rostro, en un primer momento, hasta un enmarcado con elementos abstractos en los momentos más tardíos. En el Grupo 2 de Palancho se identificaron tanto máscaras como enmarcados con geométricos internos formando conjuntos sin diferenciación cronológica (Fig. 11).

Por último, puede mencionarse que el recurso plástico utilizado en el grabado de la figura humana antes descripta -en el cual el horadado interno del cuerpo de la figura sobrepasa el contorno del mismo- de uso exclusivo del Grupo 2, fue también registrado en el sitio puneño de Antofagasta de la Sierra, uno de los enclaves más septentrionales de la iconografía rupestre Aguada (Podestá 1989:46).

\section{Grupo 3}

Dentro de este grupo se han identificado 84 motivos (más 17 de asignación dudosa) y 19 tipos de motivos, entre los que se destacan por su cantidad los tridígitos (24 motivos) y las pisadas humanas (17 motivos). Otros grabados que sobresalen, ya no por su cantidad sino por su factura más prolija y regular, son los zoomorfos (suris, camélidos, lagartija) (Fig. 5). Se caracterizan por presentar el cuerpo de tratamiento plano cuya superficie está abradida en forma uniforme, no dejando restos de roca-soporte en el interior. Un recurso plástico particular es que, en la mayoría de los casos, esta superficie no aparece contorneada por un surco (Fig.14).

Entre los abstractos son frecuentes los motivos rectilíneos como series de líneas rectas y quebradas, realizados por abradido de surcos profundos en sección $\mathrm{V}$ y muy anchos (en algunos casos de más de tres centímetros). En estos ejemplos nuevamente la técnica del abradido remueve la totalidad del soporte logrando una superficie uniformemente alisada (Fig. 15).

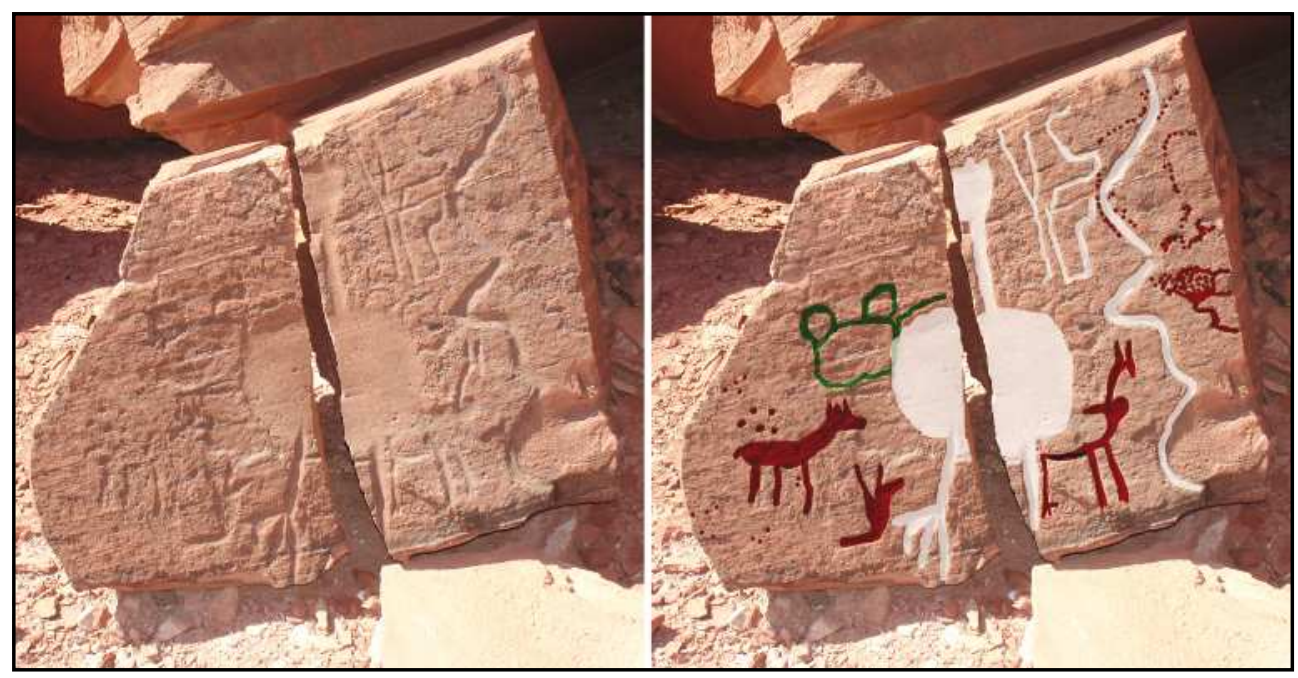

Figura 14. Grupo 2 y 3. Af. 7, Bloque 14. Suri de cuerpo plano abradido sin surco perimetral del Grupo 3 (color claro) superpuesto a camélido del Grupo 2 (colores oscuros) y reciclando felino del mismo grupo. Suri: $60 \mathrm{~cm}$ de altura. 


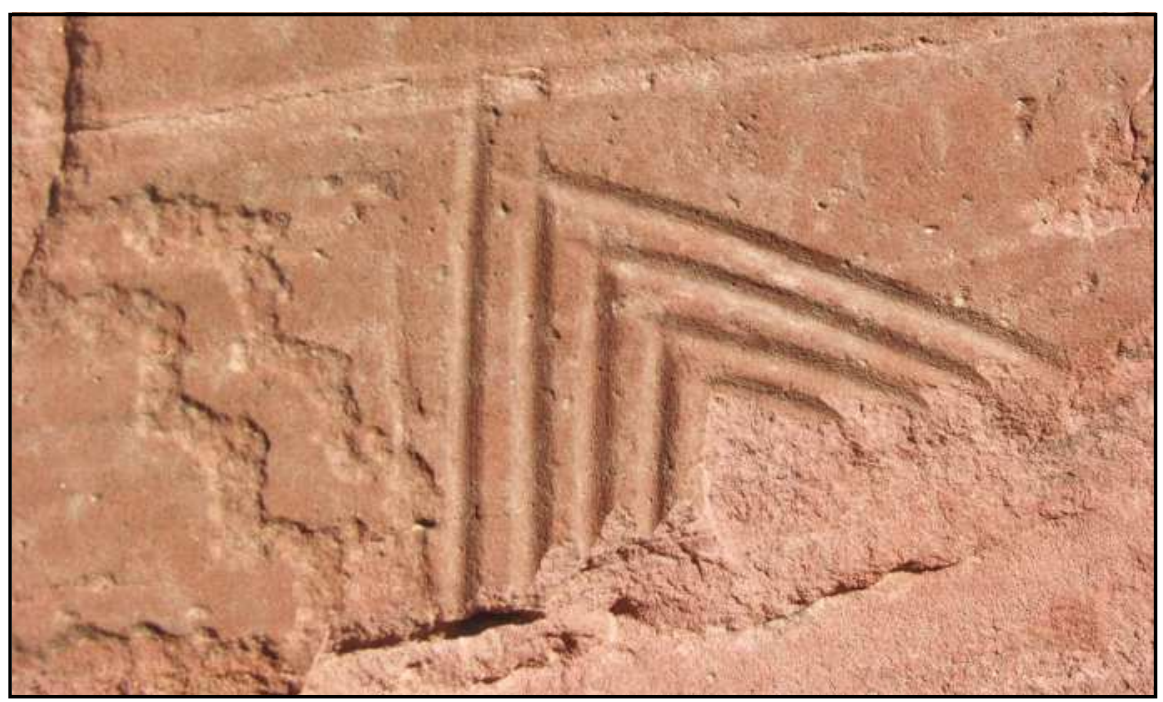

Figura 15. Grupo 3. Af.7, Bloque 9. Lineas quebradas paralelas abradidas superpuestas a línea escalonada del Grupo 1. Lineas quebradas: $20 \mathrm{~cm}$ de largo.

Este grupo tiene una distribución restringida en la localidad ya que sólo se ha identificado en los afloramientos 6 y 7 . Además de los ejemplos ya vistos donde se superponen motivos del grupo 3 sobre otros del 2 y del 1 (Fig. 14 y 15) se han registrado superposiciones de grabados del mismo grupo. Existen algunos pocos casos de reciclado, como el de la Fig. 14 donde un motivo de suri recicla el grabado de un felino del Grupo 2 dejando visible sólo la cabeza del animal. La pátina, al igual que la del grupo anterior, fue definida como pátina 2.

\section{Grupo 4}

El rasgo particular de este grupo es que no registra motivos figurativos, con excepción de los tridígitos (7 motivos). Los 39 motivos asignados se agrupan en 17 tipos entre los que prevalecen las líneas quebradas (6 motivos). Hay también líneas con extremos diferenciados y en zigzag (Fig. 16). Un motivo que identifica a este grupo es la figura escalonada. La figura se compone de una doble línea paralela recta y escalonada que se desenvuelve formando un zigzag (Fig. 17).

Las técnicas utilizadas son el inciso y el abradido poco profundo combinado con inciso que se distingue notablemente del utilizado en el Grupo 3 (Fig. 8). Tiene una mayor dispersión en la localidad en comparación al grupo anterior ya que se encuentra en los afloramientos 4, 5, 6 y 7 (Tabla 4). Se observan superposiciones y, en algunos casos, reciclado de algunos motivos preexistentes (Fig. 11, 16 y 17). Los grabados presentan la patina 3 que contrasta notablemente con la roca soporte y que indica la ejecución más reciente de este grupo de representaciones.

Buena parte de los motivos abstractos que caracterizan a este grupo guardan similitudes estilísticas con la decoración cerámica y textil Sanagasta que se desarrolló en ámbitos de la provincia de La Rioja durante el Período Tardío o de Desarrollos Regionales (1000-1480 d.C.) 


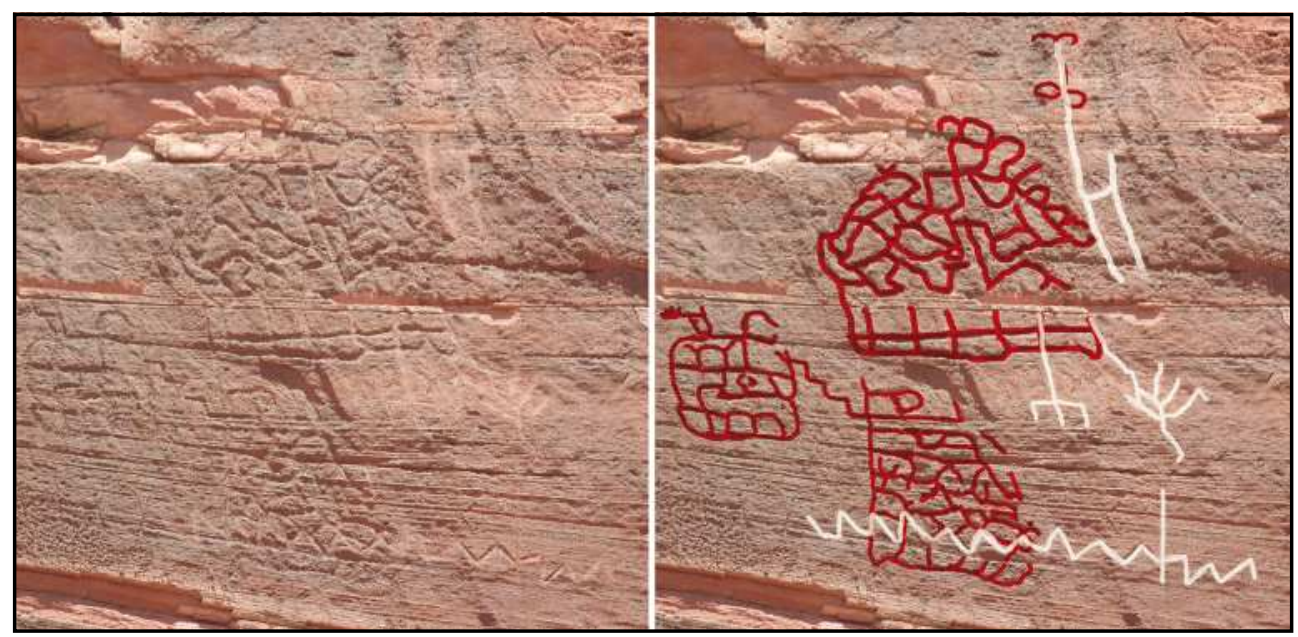

Figura 16. Grupo 2 y 4. Af.7, Pared 6A. Linea en zigzag (color claro) superpuesta a motivos del Grupo 2 (color oscuro).

(Callegari 2004; Callegari et al. 2009, entre otros). Callegari y su equipo de investigación señalan la escasa información relacionada con el estudio de las sociedades Sanagasta en comparación con la existente sobre el fenómeno Aguada en La Rioja. La presencia de las ocupaciones tardías se evidencia en las extensas superficies de terreno denudadas por la erosión (barreales), cubiertas por fragmentos cerámicos correspondientes a diferentes períodos cronológicos, reconociéndose allí la gran abundancia de vestigios propios de Sanagasta. Esta escasa información sobre los sitios tardíos se refleja también en la ausencia de referencias sobre arte rupestre de estilística de este período.

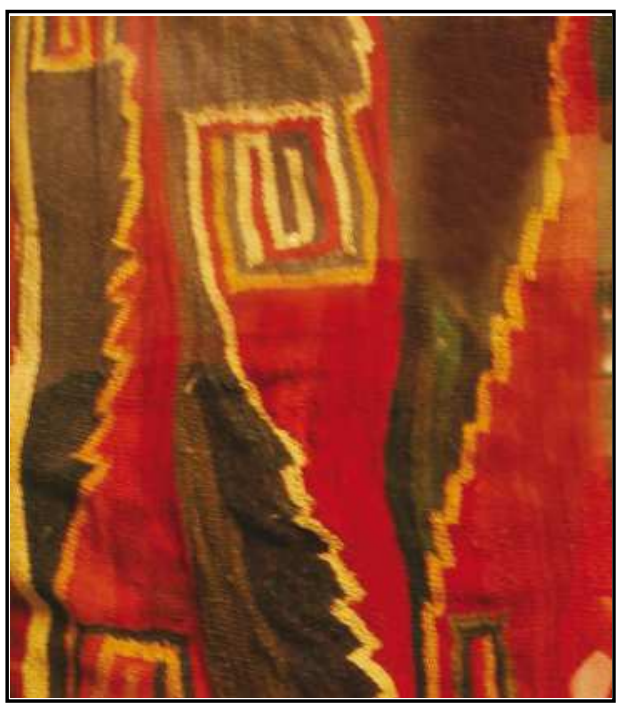

Figura17. Textil donde se aprecian diseños espirales y escalonados. Instituto de Investigaciones Arqueológicas y Museo Prof. Mariano Gambier. FFHA, UNSJ.
Entre las semejanzas estilísticas más estrechas con los grabados del Grupo 4, es posible mencionar la decoración de los refuerzos de camisas y ponchos correspondientes a contextos Angualasto (nombre con el cual se reconoce al estilo Sanagasta en San Juan) de los vecinos valles sanjuaninos. Michieli en su estudio sobre textiles tardíos de la provincia de San Juan describe varios ejemplares con decoración de espirales curvos o cuadrangulares, sucesión de triángulos escalonados y líneas oblicuas que interpreta como abstracción de atributos del cóndor macho adulto (especialmente el cuello, cresta y ojo) (Michieli 2001b, 2009; INAPL 2009:19) (Fig. 17). Las similitudes con el arte rupestre de Palancho se expresan particularmente en las figuras escalonadas como la que se ilustra en la Fig. 18 que, a su vez, comparten una morfología común con algunos motivos similares del sitio Los Colorados (Fig. 19). 


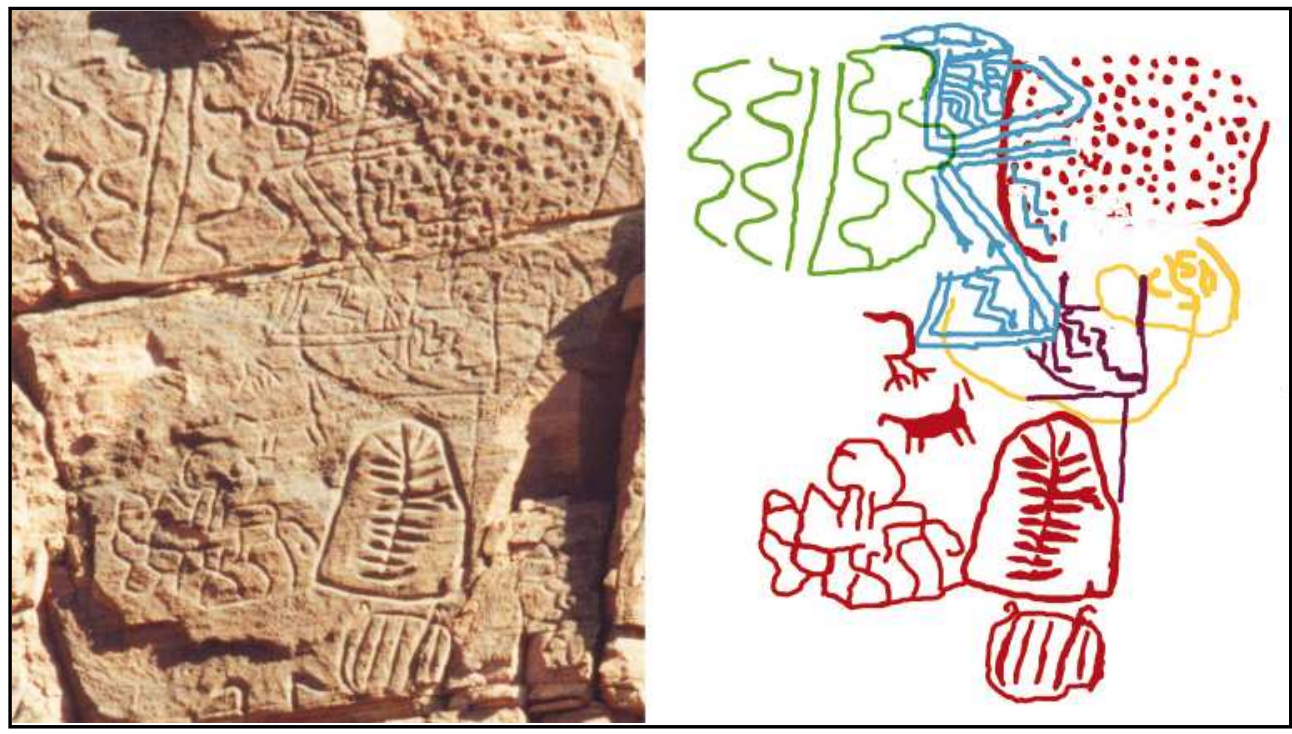

Figura 18. Grupo 4. Af. 7, Pared 7. Detalle de la superposición de la figura escalonada y en zigzag sobre un enmarcado del Grupo 2. Pared a gran altura, sin indicación de escala.

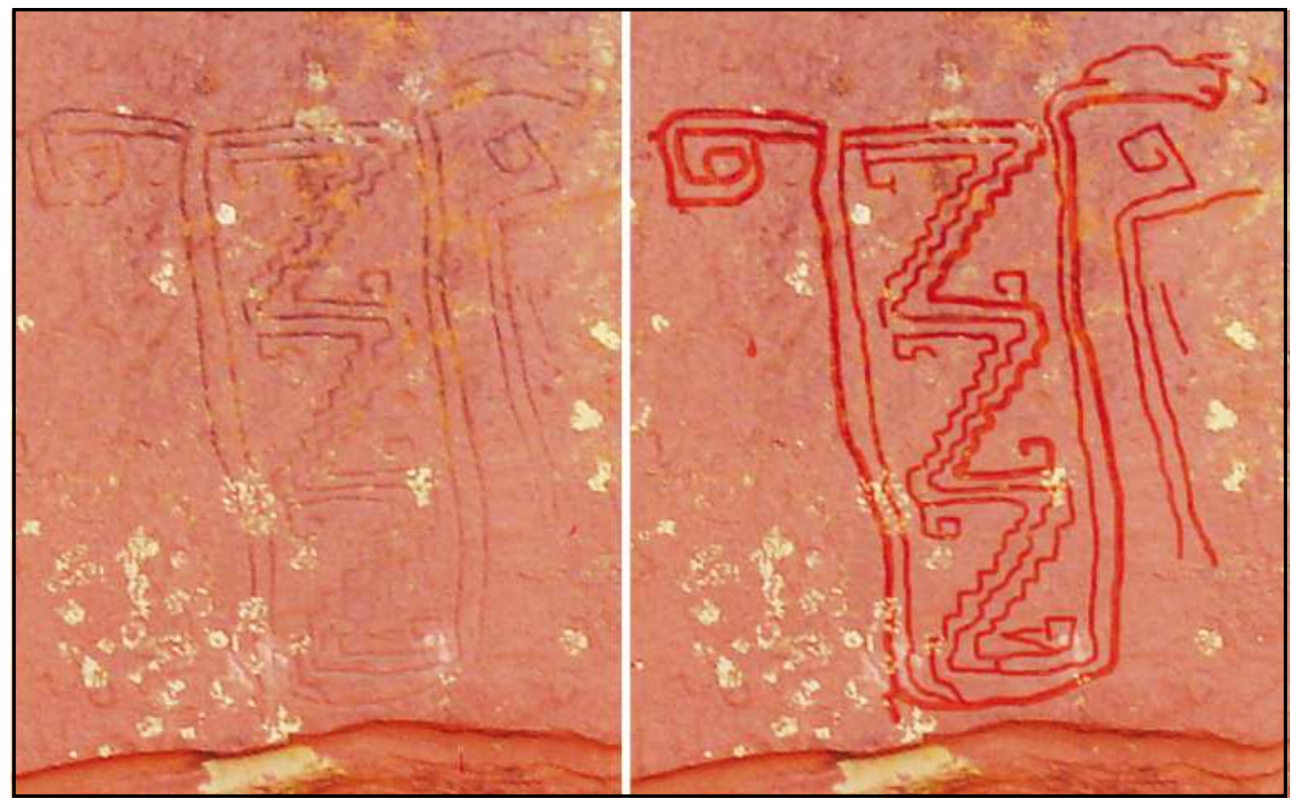

Figura 19. Sitio Los Colorados. Bloque 1. Detalle de la figura escalonada y en zigzag similar a Fig. 17. Motivo: 1,30 m de alto.

\section{Grupo 5}

Los escasos motivos históricos de la localidad están representados por tres marcas de ganado, dos fechas (1915 y 1946) y una inicial, agrupados en dos tipos de motivos. La pátina es muy clara (pátina 3) y contrastante con el soporte circundante. Están localizados en los 
afloramientos 6 y 7 y no se superponen a motivos de grupos prehispánicos si bien en un caso comparten el mismo soporte.

Estos grabados se adscriben a momentos históricos y son comparables a los registrados en el Parque Provincial Ischigualasto (San Juan) (Podestá et al. 2006 y 2011) y en diversas localidades de La Rioja (Revuelta 2008). Están relacionados con la presencia de arrieros que conducían ganado bovino hacia la Cordillera de los Andes con destino final en Chile, actividad que se concentró entre mediados del siglo XIX y principios del XX. Como se mencionó al comienzo, Palancho se ubica en las cercanías del Camino Real y de los restos de una Casa del Estado, es decir que en tiempos coloniales la zona estaba enclavada en la vía de circulación más importante existente entre Chilecito y Patquía. Si bien la práctica de la arriería fue perdiéndose gradualmente, al menos hasta 1946 -fecha más reciente grabada en Palancho- pudo haberse mantenido en esta región.

\section{Consideraciones finales}

Teniendo en cuenta una visión de conjunto de los grupos de motivos prehispánicos (1 a 4), destacamos que entre los grupos 1 a 3 existen coincidencias en cuanto a la recurrencia de algunos tipos de motivos, como por ejemplo los camélidos, suris, pisadas humanas y de suri, entre otros, si bien indicamos cierta variabilidad morfológica en algunos tipos dependiendo del momento de su ejecución (caso de los camélidos y de los suris, por ejemplo). Por su parte, las pisadas de suri o tridígitos, además de los motivos geométricos complejos y los geométricos simples (líneas rectas, quebradas, sinuosas y paralelas), son los únicos que se mantienen a lo largo de toda la secuencia prehispánica. Paralelamente a la vigencia de algunos motivos a lo largo de la secuencia de producción, enfatizamos la existencia de tipos exclusivos en ciertos grupos. Entre estos indicamos: las cruces de contorno curvilíneo, las figuras humanas (con las excepciones mencionadas) y las cúpulas en el Grupo 1; las figuras de felino, la cabeza trofeo del Grupo 2, algunos zoomorfos exclusivos (lagartija) del Grupo 3 y un motivos de triángulo y de cruz simple en el Grupo 4. Al mismo tiempo hemos destacado que las técnicas de ejecución y algunos recursos plásticos utilizados en la representación del arte rupestre-como los horadados de las figuras humanas del Grupo 2 y los incisos profundos del 3- fueron indicadores importantes a la hora de asociar temporalmente a algunas representaciones. Como por ejemplo los grupos 3 y 4 han sido separados principalmente en base a las diferentes técnicas de ejecución y a la coloración de pátina.

Ante la ausencia de mayor evidencia arqueológica, se emplearon principalmente indicadores estilísticos con el fin de intentar asignar los diferentes grupos de motivos de arte rupestre de Palancho a los momentos de ocupación humana reconocida en la provincia. Nos encontramos para ello con diversos inconvenientes: por un lado, la escasez de estudios, sobre todo en lo referido a las ocupaciones tardías de la provincia y, por otro lado, a la ausencia de una caracterización del arte rupestre del Período Tardío o de Desarrollos Regionales. La estilística Aguada, reconocible ya desde el momento de ejecución del Grupo 1 pero con una presencia muy acentuada en el estilo de los grabados del Grupo 2, es quizás la más fácilmente determinable. De esta manera, Palancho representaría una de las expresiones de arte rupestre más australes relacionadas con su dispersión meridional. Con respecto al Grupo 4, señalamos diversos elementos que remiten a la decoración cerámica y textil Sanagasta/ Angualasto. Muy preliminarmente podemos extender también esta comparación a las representaciones del Grupo 3. De esta manera, y en forma tentativa, nos aproximamos a la primera definición de un arte rupestre de estilística Sanagasta para los momentos tardíos de ocupación de la región. 
Dentro de este marco temporal general, no se descarta que las representaciones de los grupos 1 y 2, por un lado y 3 y 4 por otro, guarden una cierta contemporaneidad, dada la interacción La Aguada-Sanagasta constatada al Noroeste de esta región (Valle de Vinchina) (Callegari 2004). Podemos sugerir que esta parcial superposición temporal en Palancho podría estar explicando la persistencia de algunas representaciones a lo largo de la secuencia.

Retomando la escasa información proveniente de los sitios próximos Los Colorados y el Cementerio Quebrada de Paluque, con fechados por termoluminiscencia entre los 900 y 990 años AP, respectivamente, podemos señalar que dan un marco temporal general para el arte rupestre prehispánico de Palancho.

Cerrando la secuencia de producción de la localidad, los grabados asignados al Grupo 5 son la expresión más reciente del arte rupestre de Palancho asignada al movimiento de los arrieros durante el período histórico de fines del siglo XIX y comienzos del XX.

La reutilización de la localidad durante un extenso rango temporal -que en forma tentativa sugerimos entre los 600 d.C. hasta momentos históricos- estaría señalando a Palancho como un hito en el espacio regional a lo largo del tiempo. La monumentalidad del paisaje y las amplias condiciones de visibilidad de los paneles le dan al arte rupestre un carácter de tipo público. La ausencia de agua durante un largo período del año inhibe pensar en un asentamiento a largo plazo en las inmediaciones de Palancho. Esta condición de aridez, sumada a la ausencia de otro tipo de evidencia arqueológica (con excepción de algunos bloques con morteros) conducen a pensar que la función de la localidad estuvo acotada a la ejecución y uso del arte rupestre, si bien no descartamos que futuras investigaciones puedan abrir otras alternativas.

No se han registrado otros sitios con concentraciones de arte rupestre de la magnitud de las de esta localidad en la región, por lo tanto se podría considerar a Palancho como único por sus características. La información generada en sitios con arte rupestre próximos (Parque Provincial Ischigualasto y sectores del Norte y del Sur de la Sierra de Valle Fértil y Norte de la de la Huerta, en San Juan y en las localidades de El Chiflón, Los Colorados, Talampaya y Guasamayo -Los Llanos-, en La Rioja) permite señalar la importancia y la particularidad de Palancho en este espacio regional acotado entre las sierras y los llanos riojanos.

\section{Agradecimientos}

A nuestros compañeros del INAPL que colaboraron en los trabajos de campo: A. Gabriela Guráieb, Gaudalupe Romero Villanueva y Teresa Lagos Mármol, especialmente a esta última que trabajó en la base de datos de la localidad. Muy especialmente reconocemos la colaboración de Martha Ortiz-Malmierca, Oscar Gutiérrez y Claudio Revuelta, que desde la Agencia de Cultura de la provincia de La Rioja, nos brindaron todo su apoyo para iniciar los trabajos en Palancho y su inestimable ayuda en los relevamientos efectuados. Agradecemos al Prof. Adolfo Scaglioni quien nos hiciera conocer el sitio Palancho y nos apoyara y alentara para iniciar las investigaciones en el mismo. Por último agradecemos a los evaluadores por sus valiosos aportes.

\section{Bibliografía citada}

Aparicio, F. de

1939 Petroglifos Riojanos. Revista Geográfica Americana 11 (67) Año VI, Buenos Aires. 
Aschero, C. A.

$1999 \mathrm{El}$ arte rupestre del desierto puneño y el Noroeste argentino. J. Berenguer Rodríguez y F. Gallardo Ibáñez editores. Arte Rupestre en los Andes de Capricornio, pp. 97-135. Museo Chileno de Arte Precolombino.

Cabello, G.

2011 De rostros a espacios compositivos: una propuesta estilística para el Valle de Chalinga, Chile. Chungara, Revista de Antropología Chilena 43 (1): 25-36.

Cabrera, A. y A. Willink

1973 Biogeografía de América Latina. Departamento de asuntos Científicos, Secretaría General de la OEA. Washington. Monografía 13.

Cáceres Freyre, J.

1956 Arte rupestre de la provincia de La Rioja. Runa Vol. VIII Parte Primera, pp.60-75, Buenos Aires.

Cahiza, P.

2007 Las sociedades formativas tardías de Valle Fértil, San Juan. Comechingonia. Revista de Arqueología 10: 79-94.

Callegari, A.

2001 Los grabados del Rincón del Toro, el paisaje y su relación con el sistema iconográfico Aguada. Boletín del Museo chileno de Arte Precolombino No8: 21-33.

2004 Las poblaciones precolombinas que habitaron el sector central del valle de Vinchina entre el 900/950 y 1600/1650 d. C. (dto. General Lamadrid, La Rioja, Argentina). Relaciones 24: $81-110$.

Callegari, A. L. Wisnieski, G. Spengler, G. Rodriguez, S. Aumont

2009 Nuevas manifestaciones del arte rupestre del Oeste riojano. Su relación con el paisaje y con otras expresiones del arte Aguada. M. Sepúlveda R., L. Briones M., J. Chacama R. editores. Crónicas en la piedra. Arte Rupestre de las Américas, pp. 381-402. Ediciones Universidad de Tarapacá, Arica.

de la Fuente, N., C. Nazar y E. Pelli

1979 Arte rupestre en la región de Ancasti, prov. de Catamarca. Antiquitas 2: 408-418.

Falchi, M. P. y M. A. Torres

2010 Recursos didácticos para la valoración y conservación de sitios arqueológicos con arte rupestre. Global Rock Art. Anais do Congreso Internacional de Arte Rupestre IFRAO, FUMDHAMentos IX, vol. 4, Piauí, Brasil. Fundaçao Museu do Homen Americano, pp. 1101-1109.

Ferraro, L.

2005 Los Pizarrones: investigación, conservación y difusión de arte rupestre en el Parque Nacional Talampaya. Tesis de Licenciatura. Carrera de Ciencias Antropológicas, Facultad de Filosofía y Letras. Universidad de Buenos Aires. 
Fiore, D.

2007 The economic side of rock art: concept son the production of visual images. Rock Art Research vol. 24, No 2, pp. 149-160.

Giordano, A. y M. E. Gonaldi

1991 Manifestaciones del arte rupestre en una zona de alto interés turístico. Una política de protección. El arte rupestre en la Arqueología Contemporánea, Podestá, M.M., Hernández Llosas, M.I. y Renard de Coquet, S.F. (eds.), Buenos Aires.

Gordillo, I., M. Baldini y M. F. Kusch

2000 Entre objetos, rocas y cuevas: significados y relaciones entre la iconografía rupestre y mobiliar de Aguada. Arte en las rocas, M.M. Podestá y M. de Hoyos (eds.) SAA y AINA, Buenos Aires.

Guráieb, A. G., M. Rambla y D. Carro

2010 Primera aproximación al estudio del registro lítico y cerámico del Parque Provincial Ischigualasto (PPI). En Arqueología del Centro Oeste argentino: aportes desde las IV Jornadas Arqueológicas cuyanas, editado por R. Bárcena; pp. 91-105. XAMA Serie Monografías. INCIHUSA Mendoza.

Guráieb, A. G., E.D. Carro y M. J. Rambla

2010-2011 Una primera campaña afortunada a la Reserva Natural El Chiflón (La Rioja). Novedades de Antropología No 67:9-13.

INAPL

2009 Los Colorados: Un lugar para descubrir, AAINA, Buenos Aires.

Michieli, C. T.

2001a Textilería Aguada en el Valle de Iglesia, Provincia de San Juan. Publicaciones 24 (nueva serie). UNSJ, Fac. de Fil., Humanidades y Artes, Instituto de Investigaciones Arqueológicas y Museo, San Juan.

2001b Textiles de Angualasto: ratificación de juicios a través de cuatro fardos funerarios. Publicaciones del Instituto de Investigaciones Arqueológicas y Museo 24: 63-76, Univ. Nac. de San Juan, San Juan.

2009 Tumbas y textiles preincaicos en una zona andina meridional. Las sociedades de los paisajes áridos y semi-áridos del centro-oeste argentino (compilado por Y. Martini, G. Pérez Zavala y Y. Aguilar), pp.111-122. Universidad Nacional de Río Cuarto, Argentina.

Ortiz Malmierca, Martha

2004 Amanecer de la historia. Arqueología de La Rioja. La vida antes de la llegada de los españoles. Nexo Comunicación, La Rioja.

Podestá, M. M.

1989 Punta del Pueblo: expresiones del arte rupestre Agro-alfarero en la Puna argentina. Boletín del SIARB 3: 38-47. La Paz.

Podestá, M. M. y D. S. Rolandi.

2005 El uso del pasado y el arte rupestre de Palancho, La Rioja. Novedades de Antropología Año 14 Nº50, pp.8-9, Buenos Aires. 
Podestá, M. M., D. S. Rolandi y M. Sánchez Proaño

2005 El Arte Rupestre de Argentina Indígena. Noroeste. Union Academique InternationaleAcademia Nacional de la Historia, Buenos Aires.

Podestá, M. M., D. Rolandi, A. Re, M. P. Falchi y O. Damiani

2006 Arrieros y marcas de ganado: expresiones de arte rupestre de momentos históricos en el desierto de Ischigualasto. D. Fiore y M. M. Podestá eds. Tramas en la Piedra. Producción y Usos del Arte Rupestre. World Archaelogical Congress, AINA. SAA, Buenos Aires.

Podestá, M. M., A. Re y G. Romero Villanueva 2011 Visibilizando lo invisible. Grabados históricos como marcadores idiosincráticos en Ischigualasto (San Juan- Argentina). L. Núñez y A. E. Nielsen eds. En ruta, arqueología, historia y etnografía del tráfico sur andino, pp. 341-372. Encuentro Grupo Editor, Córdoba.

Raviña, M.G. y A.B. Callegari

1988 Mapa arqueológico de la provincia de La Rioja. Revista del Museo de La Plata (Nueva Serie) tomo IX, pp. 21-91. La Plata.

Re, A., M.M. Podestá y D.S. Rolandi

2009 Arte rupestre prehispánico en valles y quebradas del Parque Provincial Ischigualasto y su área de amortiguación (provincia de San Juan, Argentina). M. Sepúlveda R., L. Briones M., J. Chacama R. editores. Crónicas en la piedra. Arte Rupestre de las Américas, pp.413-429. Ediciones Universidad de Tarapacá, Arica.

Renard de Coquet, S.F.

1988 Sitios arqueológicos con arte rupestre de la República Argentina. Registro/Documentación. FECIC, Buenos Aires.

Revuelta, C.M.

2008 Arte rupestre de arrieros históricos en La Rioja. Nuevos sitios y descripción preliminar para su estudio en la provincia. Novedades de Antropología Año 16 No 58:9-11. Buenos Aires.

Rolandi, D., M. M. Podestá y A. Re

2003 Proyecto Documentación y Preservación de Sitios con Arte Rupestre en la provincia de La Rioja: Palancho (Paluque) y Reserva Provincial de Uso Múltiple Guasamayo. Informe del Primer Trabajo de Campo, Instituto Nacional de Antropología y Pensamiento Latinoamericano $(M S)$.

Rolandi, D., A.G. Guráieb, M.M. Podestá, A. Re, M.P. Falchi, R. Rotondaro y M.A. Torres 2009 Investigación y gestión del patrimonio cultural en Ischigualasto (San Juan ) y PalanchoLos Colorados (La Rioja). Las sociedades de los paisajes áridos y semi-áridos del centro-oeste argentino (compilado por Y. Martini, G. Pérez Zavala y Y. Aguilar), pp.449-464. Universidad Nacional de Río Cuarto, Argentina.

Schobinger, J.

1966 Nota sobre los petroglifos de Talampaya (Prov. La Rioja). Antiquitas II, pp. 1-4, Buenos Aires. 
Schobinger, J. y C. J. Gradin 1985 Arte rupestre de la Argentina. Cazadores de la Patagonia y agricultores andinos. Encuentro Ediciones, Madrid.

Torres, M. A. y N. Zubeldía

2007 Informe del primer trabajo de campo: Reserva Provincial de Uso Múltiple Guasamayo, provincia de La Rioja. Instituto Nacional de Antropología y Pensamiento Latinoamericano $(M S)$.

Troncoso, A., F. Armstrong, F. Vergara, P. Urzúa y P. Larach 2008 Arte rupestre en el Valle El Encanto (Ovalle, Región de Coquimbo): hacia una revaluación del sitio-tipo del Estilo Limarí. Boletín del Museo Chileno de Arte Precolombino 13 (2): 9-36, Santiago de Chile. 